\title{
A high-resolution modeling study of the Western Iberian Margin mean and seasonal upper ocean circulation
}

\author{
Rita Nolasco ${ }^{1, ~}{ }^{*}$, Ana Cordeiro Pires ${ }^{1}$, Nuno Cordeiro ${ }^{1}$, Bernard Le Cann ${ }^{2}$, Jesus Dubert ${ }^{1}$
}

\begin{abstract}
${ }^{1}$ Department of Physics, Campus de Santiago, Centro de Estudos do Ambiente e do Mar (CESAM), University of Aveiro, 3810-193, Aveiro, Portugal

2 Laboratoire de Physique des Océans, UMR 6523 CNRS/UBO/IFREMER/IRD, Université de Bretagne Occidentale, Brest, France
\end{abstract}

*: Corresponding author : Rita Nolasco, email address : rita.nolasco@ua.pt

\begin{abstract}
:
The mean seasonal hydrography and circulation of the Western Iberian Margin (WIM) are studied by means of a high-resolution configuration of the Regional Oceanic Modeling System. A comparison of 5 -year model averages for January and July with climatological datasets shows a general good agreement in the reproduction of the mean water mass properties and hydrographic distribution. We find that there is a prevailing tendency for slope poleward flow at about $80-100 \mathrm{~km}$ offshore at all latitudes from the surface to $1,500 \mathrm{~m}$ with strong vertical coupling. This northward flow, which is mainly along slope and amounts up to $8-10 \mathrm{~cm} \mathrm{~s}^{-1}$, exhibits several mean flow recirculation regions on its way and evidences of an offshore pathway of poleward flow. Transports at different zonal sections further confirm the poleward flow tendency with two peaks of poleward transport in summer (3-10 Sv) and winter $(2-7 \mathrm{~Sv})$. The transport time series emphasize the seasonal character of the alongshore circulation and the interannual intrinsic variability of the circulation, since the forcing fields are climatological. As a conceptual essay with the purpose of assessing the Mediterranean Water flow influence on the WIM mean circulation, a second model configuration is setup, where the Mediterranean outflow into the study domain is removed. We find that there is an attenuation of the mesoscale field, but the slope poleward flow intensifies and remains as a mean dynamical feature closer to the upper slope.
\end{abstract}

Keywords: Western Iberian Margin ; Numerical modeling ; Poleward flow ; Upwelling systems 
1 1. Introduction

3 The Western Iberian Margin (WIM) (see Figure 1, domain SD) is located between

4 two offshore large-scale oceanic systems: to the north, the North Atlantic Current

5 flowing in the NE direction; to the south, the Azores Current flowing eastward with

6 complex interactions with the Gulf of Cadiz. This region is characterized by a weak

7 large-scale circulation, mostly southward, with typical velocities of a few centimeters

8 per second, and frequently named the Portugal Current (Saunders, 1982).

9 At the coastal transition zone, the circulation along the WIM is largely influenced by

10 the presence of the atmospheric anticyclonic system named Azores High, whose

11 position oscillates between northern locations off the Iberian Peninsula during

12 summer and a southern position during winter in front of Morocco, while the Iceland

13 low intensifies leaving room for the eastward passage of low pressure systems, that

14 introduce a strong variability in the circulation along the WIM during wintertime.

15 These atmospheric regimes are the reason why in late spring and summer there is

16 coastal upwelling, that is, deep, cool, nutrient-rich waters upwell and are advected

17 equatorward, resulting in an offshore displacement of surface warm waters and

18 phytoplankton blooms (see review by Relvas et al., 2007). The thermohaline structure

19 of the water masses, consisting in large-scale temperature and salinity meridional

20 gradients, (Peliz et al., 2003) together with wind forcing, generate a system of

21 poleward currents along the Atlantic Iberian Peninsula observed mainly during

22 autumn and winter, as described in the classic references of Frouin et al. (1990) and

23 Haynes and Barton (1990) for the western Iberian Peninsula, and continuing along the

24 Bay of Biscay as described by Pingree and Le Cann (1990). This northward 25 circulation is typical of midlatitude eastern continental margins (Neshyba, 1986). A 
1 consensual denomination for this flow is the Iberian Poleward Current (IPC). The

2 classic view of the IPC presents it as an upper-slope baroclinic current, associated

3 with the downwelling of the isopycnal field in a width of about $40 \mathrm{~km}$, and positive

4 temperature and salinity anomalies from the surface down to typically $400 \mathrm{~m}$. It was

5 suggested that poleward flows are not a winter phenomenon only, but are present

6 throughout the year (see reviews by Peliz et al., 2005 and Relvas et al., 2007).

7 Below the surface waters, the Mediterranean Water (MW) is of central importance for

8 the circulation in the region. The MW enters the domain through the Strait of

9 Gibraltar and flows at depth along the Gulf of Cadiz and the WIM slope. The

10 resulting intermediate-level current is called Mediterranean Undercurrent (MU) in the

11 Gulf of Cadiz (Ambar and Howe, 1979) and Mediterranean Water Vein along the

12 WIM (Daniault et al., 1994); it should be noted that the Mediterranean Water Vein is

13 not the only pathway by which MW reaches the Atlantic. Upon exiting the $300 \mathrm{~m}$

14 deep Strait of Gibraltar, the dense MW flows downslope within the Gulf of Cadiz

15 until it reaches neutral buoyancy; afterwards, along the WIM, it flows at mid-depths

16 often in two cores, typically at $800 \mathrm{~m}$ (the upper core), where a temperature maximum

17 is reached, and at $1200 \mathrm{~m}$ (the lower core), the depth at which the salinity maximum is

18 found. The signature of the hydrographic properties of both cores decreases (notably

19 the upper core) in the poleward direction along the WIM. Associated with this flow,

20 there are mesoscale structures that are formed and which are responsible for a relevant

21 part of this water mass properties transport: the Mediterranean eddies (Meddies),

22 anticyclonic vortices with radii of several tens of kilometers, centered around $700 \mathrm{~m}$

23 and $1300 \mathrm{~m}$ deep (Bower et al., 1995). Meddies propagate typically southwestwards

24 into the North Atlantic (Richardson et al., 2000). 
1 The numerical study of the circulation of the WIM is a challenge for modelers, for

2 several reasons: i) the presence of a narrow shelf and a steep slope (up to $10 \%$ ), as

3 well as the presence of numerous canyons and promontories, requiring high resolution

4 to properly resolve the shelf/slope circulation in presence of realistic stratification ; ii)

5 the presence of a unique oceanographic feature, which is the MU, generated at the

6 Strait of Gibraltar and spreading into the NE Atlantic giving rise to the large scale

7 MW anomaly; iii) the influence of the open ocean circulation (the Azores Current

8 system and meridional pressure gradients) on the coastal transition zone, that forces

9 the circulation in this region.

10 In this way, there is a need for high-resolution studies that may deal with the factors

11 mentioned above, with special attention to the different scales that influence the

12 circulation of the WIM, ranging from the few kilometers of the Strait of Gibraltar

13 dynamics, to the hundreds to thousands kilometers scale of the Azores Current

14 system. These features compelled us to perform a multi-scale simulation based on

15 nesting techniques, as detailed below.

16 In what concerns numerical modeling regional studies at the full scale of the region,

17 some previous works contributed to the study of this particular circulation. Some of

18 them were carried out at a low resolution of about $9 \mathrm{~km}$ (Stevens et al., 2000; Coelho

19 et al., 2002) and focused on spring and winter circulation; others were idealized

20 studies at a high resolution (Røed and Shi, 1999; Peliz et al., 2003). Batteen et al.

$21(2000,2007)$ carried out sensitivity studies in order to assess the different mechanisms

22 controlling the circulation in the region. The study by Serra et al. (2010) resolves the

23 circulation in this region with realistic forcing and high resolution, focusing on the

24 study of the influence of the MW vein on the surface circulation, with emphasis on

25 the mesoscale phenomena. On the other hand, from the point of view of operational 
1 oceanography of the Western Iberian Margin, Mateus et al. (2012) focused on the

2 application of an operational configuration $\left(\sim 1 / 16^{\circ}\right.$ resolution) to discuss its potential

3 for products and services for scientific and coastal management activities.

4 In the neighborhood of the region, and also at a high resolution, Friocourt et al. (2007)

5 and Peliz et al. (2007) studied the Bay of Biscay and the Gulf of Cadiz circulation,

6 respectively.

7 Although the three major distinctive phenomena of the WIM, referred to above:

8 upwelling, poleward flow and Mediterranean outflow, have an independent dynamical

9 origin, they are intimately linked, and should be studied in an integrated manner. This

10 is the main challenge for the present work.

11 The present configuration includes the WIM region, the Western Bay of Biscay and

12 the Gulf of Cadiz. It is intended to study the equilibrium hydrography and circulation

13 in the surface layers, the underlying Central Waters, and the intermediate

14 Mediterranean Waters.

15 In order to do that, numerical simulations for the WIM region forced by

16 climatological heat and momentum fluxes were set up. In the present work we intend

17 to discuss the mean circulation that arises from the intrinsic variability of the model in

18 the absence of any external interannual atmospheric or oceanic forcing.

19 Using climatological forcings the model results achieve a realistic circulation,

20 reflected by a mesoscale field (not discussed in this work), and a mean field, which is

21 described and discussed in the light of the observations. The results discussed in this

22 work intend to contribute to the understanding of the IPC, not only during winter as is

23 classically studied, but also in the summertime, when the dominant poleward flow on

24 the outer slope coexists with equatorward flow, in agreement with the observations. It

25 is also intended to discuss the generation of vorticity structures of the mean flow 
1 along the WIM, and its relation to the topography, and the large scale circulation. The

2 links between the surface and the intermediate circulation are also discussed, as is the

3 resulting circulation in the hypothetical case of suppression of the MW overflow.

4 The outline of this work is as follows: in section 2, we describe the methodology and

5 the ocean model configurations set up for this study; in section 3 we present a

6 comparison of model results with observational data and we characterize the mean

7 annual and seasonal hydrography and circulation of the WIM region; in section 4 we

8 study the influence of the MW in the WIM circulation; and in section 5 we discuss the 9 results.

11 2. Methods and Data

\subsection{Ocean Model}

15 A high-resolution nested configuration of the Regional Ocean Modeling System 16 (ROMS) (Shchepetkin and McWilliams, 2003) is used to simulate the seasonal 17 dynamics of the Iberian System. ROMS is a split-explicit, free-surface, topography

18 following coordinate model, designed to resolve regional problems (Shchepetkin and

19 McWilliams, 2005). ROMS solves the incompressible primitive equations based on 20 the Boussinesq and hydrostatic approximations, and is coupled with

21 advection/diffusion schemes for potential temperature and salinity as well as a

22 nonlinear equation of state. The advection scheme is based on the work done by

23 Marchesiello et al. (2009), in order to reduce spurious diapycnal mixing in sigma-

24 coordinate models characteristic of higher-order diffusive advection schemes. This

25 scheme involves the split of advection and diffusion, as a biharmonic operator. 
1 Vertical mixing consists in the KPP (K-profile parameterization) scheme (Large et al.,

2 1994).

$4 \quad$ 2.1.1 Model Configuration

5

6 a. Large domain

7 The strategy to manage a large range of scales consists in the implementation of

8 a two-domain approach, as shown in Figure 1. A large-scale first domain (FD) is

9 run independently in order to provide initial and boundary conditions to our

10 second domain (denoted SD hereafter) through an offline nesting. The first

11 domain horizontal resolution is $1 / 10^{\circ}(\sim 9.5 \mathrm{~km}$ in longitude), and the main aim

12 for this domain is to resolve the large-scale circulation features such as the

13 Azores Current, and their interaction with the Atlantic margin of the Iberian

14 Peninsula.

15 For this domain, 30 sigma vertical levels are used, with a stretching factor of $\theta_{s}=7$

16 and $\theta_{b}=0$ to conserve a good near-surface resolution over the entire domain. The

17 bathymetry is based on ETOPO1 (Amante and Eakins, 2009), with corrections

18 ,near the slope and a smoothing filter to fulfill the $r=\Delta h / 2 h$ criterion (Haidvogel

19 and Beckmann, 1999), $r<0.2$.

20 The World Ocean Atlas 2009 (WOA-2009) climatology is used as the initial value

21 for the temperature (Locarnini et al., 2010) and salinity (Antonov et al., 2010)

22 fields, and also to recycle these fields along the nudging bands, providing open

23 boundary conditions. Surface fluxes are obtained from the Comprehensive

24 Ocean-Atmosphere dataset (COADS) (da Silva et al., 1994), interpolated to the 25 grid with the Roms_tools (Penven et al., 2008) package. This climatology derived 
1 from the NOAA global data retrieval program (http://icoads.noaa.gov) and

2 consist in one value per month for each parameter, computed for the time period

3 1945-1989. That is, COADS has no interannual variability, only seasonal. Its

4 spatial resolution is of 0.5 degrees for all parameters except for sea surface

5 salinity, for which it is of 1 degree. Initial velocities are zero, and monthly

6 geostrophic velocities (with level of reference $1200 \mathrm{~m}$ ) and Ekman velocities are

7 computed from the climatology and applied along the open boundaries.

8 The Mediterranean undercurrent is introduced by nudging, applied to the Gulf of

9 Cadiz and Western Iberia as described in Peliz et al. (2007), in order to restore

10 the hydrographic properties ( $\mathrm{T}$ and $\mathrm{S}$ ) of the Mediterranean levels, so as to

11 generate realistic Mediterranean water hydrographic properties.

12 The open boundary conditions were based on Marchesiello et al. (2001). These

13 conditions are suitable for long time integration, and are characterized by inflow

14 (outflow) nudging timescales of 1 (360) days for tracers, and 10 (360) days for

15 momentum respectively. Sponge layers $120 \mathrm{~km}$ wide were applied along the

16 edges, with a lateral viscosity coefficient ranging from $600 \mathrm{~m}^{2} / \mathrm{s}$ at the boundary

17 to zero in the interior. Explicit viscosity and diffusivity is null, and a linear drag

18 formulation with coefficient $r=3 \times 10^{-4} \mathrm{~m} \cdot \mathrm{s}^{-1}$ is applied at the bottom. The

19 objective of the large grid is to achieve a good representation of the Azores

20 Current transport and the connection of the Azores Current with the Gulf of

21 Cadiz where the western and southern boundary of the high-resolution grid is

22 located.

24 b. High-resolution domain 
1 The target domain, SD, (second domain, see Figure 1), has a horizontal resolution

2 of $1 / 27^{\circ},(\sim 3 \mathrm{~km}$ in longitude), and includes the Gulf of Cadiz, the WIM, and part

3 of the western Bay of Biscay, extending for $\sim 1300 \mathrm{~km}$ in the meridional

4 direction, from $34^{\circ} \mathrm{N}$ to $46^{\circ} \mathrm{N}$. In the zonal direction, the domain extends from the

5 Strait of Gibraltar, located at $5.5^{\circ} \mathrm{W}$ to $12.5^{\circ} \mathrm{W}$, representing a width of about $6 \sim 600 \mathrm{~km}$.

7 Sixty sigma vertical levels with $\theta_{s}=4$ and $\theta_{b}=0$ are used to properly resolve the

8 Mediterranean undercurrent with enough near-bottom resolution. In this way,

9 the grid has $60 \times 188 \times 389$ cells.

10 The topography by Sibuet et al. (2004) was used, it has a resolution of $\sim 1 \mathrm{~km}$ and

11 was smoothed in order to fulfill the same r-factor criterion (r-factor less than 120.2 ) of the large-scale domain.

13 The forcing for this high-resolution configuration domain is the same as the one 14 used for the large scale FD domain. The initialization and the boundary 15 conditions are obtained using year 5 from FD, with average data stored every 3 16 days. To test the sensitivity of the model results to this choice, an additional 17 experiment to the main simulation, was run using year 7 of FD simulation, 18 instead of the year 5, showing results similar to the main run ones described 19 below.

20 Also, like for the large-scale simulation, a nudging sponge layer is introduced.

21 Concerning the boundary conditions of the SD domain, radiation conditions of

22 Marchesiello et al. (2001) are also used. The nudging coefficients at the edges are

23 the same as the ones used for FD configuration. However, the sponge layers at

24 the edges are applied to a band of $40 \mathrm{~km}$, with a lateral viscosity coefficient 25 ranging from $200 \mathrm{~m}^{2} / \mathrm{s}$ at the boundary to zero at the interior of the domain. A 
1 quadratic drag coefficient of $5 \times 10^{-3}$ is used for the bottom friction

2 parameterization. At the Strait of Gibraltar, at the southeastern boundary, the

3 water exchange with the Mediterranean basin is explicitly represented in the

4 domain, through a fixed boundary (as in Peliz et al., 2007): it consists in the

5 imposition of vertical profiles of temperature, salinity and zonal velocity at the

6 boundary located at the Strait. This condition is designed to setup a two-layer

7 system consisting in a transport of $0.8 \mathrm{~Sv}$ of Atlantic water leaving the domain

8 through the surface layer, and $0.7 \mathrm{~Sv}$ of Mediterranean water entering the

9 domain through the lower layer. No attempt to introduce seasonality or

10 interannual variability in these fluxes was done. The process of entrainment of

11 Atlantic Central Waters with the MU is also parameterized by increasing the

12 viscosity and diffusivity coefficients in a region in which the MW is strongly

13 mixed with the overlying Atlantic waters, until the MW vein forms along the

14 northern slope of the Gulf of Cadiz.

15 The inflow of freshwater in the ocean, originating from the main rivers of the

16 region (the most important rivers are identified in Figure 1), is included. For the

17 Portuguese rivers, climatological values were provided by INAG (Water Institute

18 of Portugal); the information on the Spanish rivers was given by Barja and

19 Lestegás (1992).

20 The spin-up time for this domain, during which the Kinetic Energy stabilizes, is 5

21 years, as the adjustment time of the MU along the western and northern Iberian

22 Margin is quite a slow process. Thus, the model is run for 14 years, and the 23 analysis presented here is done for years 10 to 14 , in order to show the seasonal 24 and interannual variability during that period. 
1 c. Solution without Mediterranean Water

2 A sensitivity experiment is performed in order to study the resulting circulation

3 without the MW spreading through the Strait of Gibraltar. For that, the large

4 scale domain FD is run for 15 years, with initial conditions from the World Ocean

5 Atlas 2009. The condition to maintain MW outflow was relaxed by turning off the

6 nudging condition applied at the Gulf of Cadiz, until the effect of the MW salinity

7 and temperature anomalies disappears as much as possible by diffusion.

8 Boundary conditions for SD are built from the results of this FD configuration,

9 with a closed boundary condition at the Strait of Gibraltar. SD is then run

10 following the same methodology described in the previous section for 14 years.

$12 \quad 2.2$ Climatology and Satellite Products

14 In the following section, model output is compared to climatological data. Two

15 datasets were chosen to carry out this comparison: the recent climatological

16 GHER atlas for the Northeast Atlantic (Troupin et al., 2010) (hereafter GHER-

17 NEA climatology) and satellite products. The GHER-NEA climatology was chosen

18 for its high resolution ( 0.1 degree), which properly resolves the slope and shelf

19 regions, unlike most available climatologies, and both temperature and salinity

20 are compared to model results. For the sea surface temperature (SST), the

21 comparison is carried out with data from the Advanced Very High Resolution

22 Radiometer (AVHRR) of the National Oceanic and Atmospheric Administration

23 (NOAA). The data was extracted from the EUMETSAT Ocean \& Sea Ice Satellite

24 Application Facility (OSI-SAF) (www.osi-saf.org) and was made available by

25 CERSAT (IFREMER, France). The product has an approximate resolution of $2 \mathrm{~km}$. 
1 The final data consists in 7-year averages, corresponding to years 2002 to 2008,

2 for January and July, of the night satellite sweep (hereafter satellite climatology).

4 3. Results

6 The first part of this section is dedicated to introducing the main features of the

7 hydrography of the region, assessing the reliability of the model in resolving the

8 hydrography of WIM and its seasonal variability, and comparing model output

9 for SD with the climatological data. This comparison is carried out by means of

10 surface horizontal field maps, $\theta-S$ diagrams for water mass characterization and

11 vertical sections of hydrographic fields along different latitudes. The second part

12 of this section focuses on studying the mean seasonal circulation of the region

13 and the vertical structure of the flow from model output, through velocity fields

14 and the analysis of meridional transport. A second solution without MW as

15 described above is also analyzed at the end of the section.

17 3.1 First domain model configuration.

19 The FD domain was designed to solve the large scale circulation in order to 20 provide boundary conditions to the target domain SD. It is not intended to

21 discuss the resulting circulation from this domain, but to show an example of

22 how the large scale circulation is solved for this domain. For that purpose, a EKE

23 comparison between altimetry and FD output is done in Figure 2. Altimetry

24 weekly data was obtained from AVISO for the period October 1992 to July 2011.

25 The signature of the Azores Current is clear between $33^{\circ} \mathrm{N}$ and $36^{\circ} \mathrm{N}$, and the 
1 signal extends eastwards to $\sim 12^{\circ} \mathrm{W}$ in both. There is also evidence of the North

2 Atlantic Current at the northwestern corner of the FD domain. In terms of

3 magnitude, EKE is more intense in ROMS for the Azores Current, and more

4 intense in AVISO for the North Atlantic Current. Nevertheless, we find that the

5 comparison is acceptable and we conclude that FD is reproducing correctly the

6 regional dynamics. Other diagnostics (not shown) were done in order to check

7 that the large scale hydrography and circulation of FD domain are suitable for

8 use as boundary conditions for the target domain, SD.

103.2 Hydrography and comparison to climatological data

12 3.2.1 Surface Fields

14 Figure 3 (4) presents the January (July) mean sea surface temperature (SST,

15 upper row) and salinity (SSS, lower row) of both SD and climatology, as well as

16 the difference field between the modeled and the climatological fields.

18 a. Winter

19 During winter (Figure 3), both SD and climatologies show the existence of a

20 meridional gradient of sea surface temperature and salinity. Moreover, a tongue

21 of saltier and warmer water centered at approximately $9.5^{\circ} \mathrm{W}-10^{\circ} \mathrm{W}$ is associated

22 with the poleward advection of waters of subtropical origin, frequently referred

23 to in the literature as the Iberian Poleward Current (IPC, Álvarez-Salgado et al.,

24 2003). Although this tongue is visible in both SST and SSS, it is less evident in the

25 SST satellite field. Furthermore, the poleward penetration of the climatological 
1 tongue reaches farther north than the SD one, causing a difference of about -0.1

2 in salinity between $39^{\circ} \mathrm{N}$ and $42^{\circ} \mathrm{N}$.

3 Along the continental shelf region, north of the Estremadura Promontory $\left(39^{\circ} \mathrm{N}\right)$,

4 we observe the presence of a band of buoyant fresher and colder waters, in the

5 SST and SSS climatologies, as well as in the SD averages. This band is associated

6 with the presence of winter river inflow along the western coast, mainly

7 contributed to by Tagus, Mondego, Douro, Minho and the Galician Rias rivers

8 (see Figure 1). This fresh water signature remains trapped on the continental

9 shelf, generating the Western Iberian Buoyant Plume (WIBP) (Peliz et al., 2002,

10 Otero et al. 2008).

12 b. Summer

13 During summer (Figure 4), the most important phenomenon observed is coastal

14 upwelling induced by the predominant equatorward winds along the WIM,

15 which result in the presence of a coastal band of cold and fresh waters.

16 The main patterns of the July average temperature and salinity for the offshore

17 region are well reproduced in $\mathrm{SD}$, resulting in small temperature and salinity

18 differences (Figure 4 c, f). However, SD tends to overestimate the intensity of the

19 upwelling phenomenon, and therefore exhibits a coastal water band that is

20 colder than the satellite climatology. As discussed by Veitch et al. (2010), and

21 references herein, the climatological winds do not account for the drop-off of the

22 wind stress in the neighborhood of the coast.

23 There are also regions in which SD, on the contrary, overestimates the surface

24 temperature. Along the Galician coast, north of Cape Finisterre, unlike SD results, 
1 filaments like the Finisterre filament $\left(43^{\circ} \mathrm{N}\right)$, are frequently observed by satellite

2 in this area (Torres et al., 2003).

3 Other regions where SD temperatures are warmer than observed are the

4 northern Gulf of Cadiz (Portuguese southern coast) and the northern coast of

5 Morocco. These regions are influenced by gap winds, that consist in strong

6 easterly winds associated to pressure differences between both sides of the

7 strait of Gibraltar (Peliz et al., 2009), not represented in the climatological winds.

8 The summer SSS field (Figure 4d) is characterized by the upwelling of Eastern

9 North Atlantic Central Waters of northern origin $\left(\right.$ ENACW $_{\mathrm{sp}}$, see section 3.1.2 for

10 details), which is advected southward. This upwelled water has a typical salinity

11 of about 35.8. Overlying the upwelled Central Water, there is a low salinity

12 surface water (lower than 35.7) observed in the GHER-NEA climatology (Figure

$134 \mathrm{e}$ ), which is associated with the remnant of the WIBP advected offshore by

14 Ekman transport, giving rise to a low salinity plume at the surface.

$16 \quad 3.2 .2$ Water Masses

18 The main water masses of the upper layers observed in the region of study along

19 the WIM originate from the subpolar or the subtropical branches of the Eastern

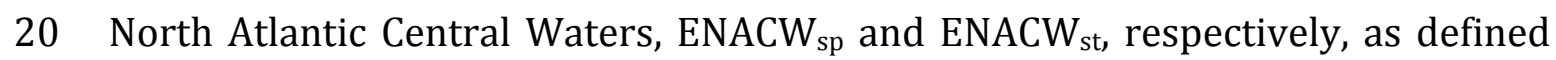

21 by Ríos et al. (1992). Below the Central Waters lies the Mediterranean Water

22 (MW) that flows through the Gulf of Cadiz and the entire basin with a typical

23 tongue structure, reaching the Bay of Biscay as described in the literature and as

24 observed in the available climatologies (WOA-2009; Reynaud et al., 1998; Iorga

25 and Lozier, 1999; Troupin et al., 2010). Below $1500 \mathrm{~m}$, there is the signature of 
1 the Labrador Sea Water, described by Paillet et al. (1998). Although its

2 hydrographic properties are reasonably well represented in SD (not shown), this

3 water mass, as well as the deeper layer North Atlantic Deep Water, is not

4 discussed in this work.

5 To compare the SD water mass properties to the climatological values, $\theta-S$

6 diagrams were elaborated for two boxes $\left(1^{\circ}\right.$ latitude $\times 1^{\circ}$ longitude) centered at

$710^{\circ} \mathrm{W}$ and $38^{\circ} \mathrm{N}$ and $42^{\circ} \mathrm{N}$ (see Figure 1 for location). These diagrams are

8 displayed in Figure 5. For each box, monthly (January, April, July and October)

9 mean profiles of potential temperature and salinity were calculated for years 10

10 to 14 of the simulation (one dashed line per year, in order to show the

11 interannual variability), and are superimposed to the GHER-NEA climatology 12 (solid line).

13 The seasonal evolution of the thermohaline properties of the Central and surface

14 waters is reproduced by SD, when compared to the climatological values. As for

15 the Central Water properties of both SD and climatology, by comparison with the

16 standard straight lines in the $\theta-S$ space for ENACW st $_{\text {and }}$ ENACW $_{\mathrm{sp}}$, it is clear that

17 the northern (southern) region is more influenced by the presence of the

18 subpolar (subtropical) branch of the ENACW.

19 For the southern region, in January (Figure 5a), the Central Waters have their

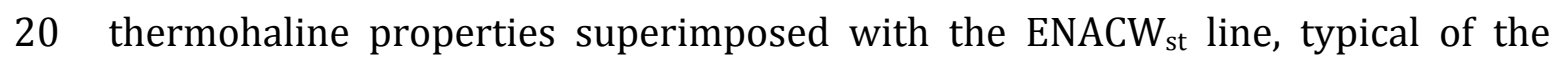

21 waters that give origin to the IPC. Below the surface, salinity decreases linearly

22 to a minimum of 35.7, and increases downwards because of the influence of the

23 underlying MW mass. In April (Figure 5b), a decrease of the surface salinity

24 maximum is observed, associated with the start of the upwelling season. During

25 summer (Figure $5 \mathrm{c}$ ), the seasonal heating modifies the $\theta-S$ structure at the 
1 surface, increasing the temperature of the surface layer. Furthermore,

2 interannual variability of the temperature in the surface layers is observed. The

3 MW mass is reproduced in SD, ranging from 36.2 to 36.35 , which includes the

4 climatological value. In October (Figure 5d), after the upwelling season, the

5 signature of saltier surface waters associated to the IPC is visible both in the SD

6 and the climatology, although SD underestimates the surface salinity by about -

$7 \quad 0.1$ units.

8 Regarding the northern region (centered at $42^{\circ} \mathrm{N}, 10^{\circ} \mathrm{W}$, Figure 5 e-h), the

9 seasonal evolution of the $\theta-S$ field follows a pattern similar to the one described

10 for the southern region, the main differences being observed in the salinity field

11 at the surface levels, with lower maximum values of salinity both in winter and in

12 summer. At the MW levels the salinity signature decreases in the poleward

13 direction as expected.

14 Overall, the SD configuration not only follows the seasonal cycle of temperature

15 and salinity for the surface and central waters, but also reproduces the MW

16 hydrographic properties, although some negative biases are observed (as well as

17 in the MW core depths, as discussed later).

\section{$19 \quad$ 3.2.3 Vertical Structure}

21 As a complementary analysis of the water masses in the two regions discussed

22 above, we now study the vertical distribution of the hydrographic properties,

23 and compare the modeled values with the GHER-NEA climatology. The aim is to

24 show and discuss the modeled temperature and salinity fields and to compare

25 them to climatological values across two latitudes, $42^{\circ} \mathrm{N}$ and $38^{\circ} \mathrm{N}$, 
1 representative of the northern and southern WIM, respectively. The averages for

2 SD were computed for January and July of simulation years 10 to 14 , down to $31500 \mathrm{~m}$ in depth.

4

5 a. Winter Hydrography

6 At $42^{\circ} \mathrm{N}$ (Figure $6 \mathrm{a}, \mathrm{c}$ ), the winter distribution of temperature and salinity shows

7 a general downward sloping of the isolines in the upper slope region (down to

8 about $400 \mathrm{~m}$ ), between $9.5^{\circ} \mathrm{W}$ and $11^{\circ} \mathrm{W}$. This downward tendency is associated

9 with the presence of the IPC during wintertime, with salinities higher than 35.9

10 and temperatures around $14.5^{\circ} \mathrm{C}$ (Figure 6c). The SD IPC (Figure 6a) shows

11 evidence of this poleward advection at the surface; however, there is a bias of 12 about $-1^{\circ} \mathrm{C}$ in temperature and about -0.1 in salinity. On the other hand, the 13 salinity minimum of ENACW sp of 35.65 (see Figure 5e) is reached at depths 14 around $400 \mathrm{~m}$, shallower than the climatological minimum (450 m). Below that 15 depth lies the MW and thus the salinity field values increase accordingly to 36 16 near the slope at an approximate depth of $900 \mathrm{~m}$, which is -0.1 fresher and $100 \mathrm{~m}$ 17 shallower than the climatological value.

18 For the southern latitude, $38^{\circ} \mathrm{N}$ (Figure $6 \mathrm{~b}, \mathrm{~d}$ ), the surface layers are

19 characterized by the presence of saltier and warmer waters when compared to

20 the northern section. In January, for the surface and central water range, the

21 hydrographic properties reflect the straight line observed in the $\theta-S$ diagrams

22 (Figure 5a). Concerning the MW, below the ENACW, the SD temperature 23 maximum $\left(\sim 12^{\circ} \mathrm{C}\right)$ associated with the upper core of MW does not reach as far

24 offshore as the climatological one (extending to $10.5^{\circ} \mathrm{W}$ whereas in SD the 25 isotherm is close to the slope), but the depth at which they are found (800 $\mathrm{m}$ ) is 
1 the same. On the other hand, the lower core SD MW salinity maximum, 36.2, is

2 underestimated ( -0.1 bias in $S)$, as it is the depth at which this maximum is found

3 (about $1000 \mathrm{~m}$ in SD and $1200 \mathrm{~m}$ in the climatology). Below the $\mathrm{MW}$, the

4 transition to LSW in SD is located at depths lower than the climatological value.

6 b. Summer Hydrography

7 Like the winter situation, the summer vertical structure is analyzed for zonal

8 sections at $42^{\circ} \mathrm{N}$ and $38^{\circ} \mathrm{N}$. At the northern section (Figure 7 a, c) the summer

9 hydrography is well characterized by the presence of coastal upwelling, which

10 affects clearly the near-surface temperature field distribution on the continental

11 shelf. The isotherms warmer than $14^{\circ} \mathrm{C}$ outcrop on the shelf, generating a front in

12 the numerical configuration. Note that the GHER-NEA climatology shows

13 evidence of upwelling, although the frontal structure is smoothed, as expected

14 from an observational climatological dataset.

15 The upwelling of the isothermal field extends down to the $13^{\circ} \mathrm{C}$ isotherm at 16 approximately $200 \mathrm{~m}$ in both SD and climatology. In the surface layers, summer

17 salinity is lower than during winter, because the signature of ENACW st is not

18 observed (Figure 5g) as the upwelled waters have a Northern origin. A minimum

19 of salinity is nevertheless observed, like in winter, with the 35.6 isohaline located

20 at approximately $400 \mathrm{~m}$ depth.

21 Concerning the MW distribution in July, at $42^{\circ} \mathrm{N}$ there are no significant

22 differences with respect to wintertime in the climatology: the same salinity

23 maximum is found at approximately $1000 \mathrm{~m}$, enclosed by the 35.9 isohalines

24 between 700-800 m and 1200-1300 m. In SD, the MW vein seems to be squeezed

25 and the temperature field is shallower by about $100 \mathrm{~m}$ with respect to the winter 
1 equilibrium depth, as observed by Garcia-Lafuente et al. (2008). These authors

2 related the shallowing of the MW vein to the mesoscale field associated with the

3 MW vein, which may originate from the variability of the wind field.

4 The southern section, $38^{\circ} \mathrm{N}$ (Figure $7 \mathrm{~b}, \mathrm{~d}$ ), during summer is also affected by

5 upwelling. In this case the outcropped isotherm is $15^{\circ} \mathrm{C}$ in $\mathrm{SD}$ against $17.5^{\circ} \mathrm{C}$ in

6 the climatology. At the levels of the MW vein, the main difference between SD

7 and climatology is the $200 \mathrm{~m}$ depth difference in the location of the salinity

8 maximum, whereas SD reaches the same climatological maximum of 36.3.

10 c. Winter vertical meridional section.

11 The surface layers meridional distribution of temperature and salinity fields

12 along the WIM at $11.5^{\circ} \mathrm{W}$ (Figure 8 ) shows evidence of a large scale gradient,

13 with southern warmer and saltier waters of subtropical origins, and northern

14 colder and fresher waters of subpolar origins. A frontal region, frequently

15 observed between $38^{\circ} \mathrm{N}$ and $40^{\circ} \mathrm{N}$, and denoted by Western Iberia Winter Front

16 (WIWF) (Peliz et al., 2005), separates both regions.

17 This meridional density gradient is partly at the origin of the Iberian Poleward

18 current system (Peliz et al., 2003). A proper representation of the meridional

19 distribution of hydrographic fields is needed to obtain a realistic poleward

20 current system along the WIM.

21 A comparison of ROMS monthly averages of temperature and salinity and the

22 GHER-NEA climatological fields for January was done (Figure 8).

23 We observe similar meridional gradients of temperature and salinity in the

24 upper levels $(0-200 \mathrm{~m})$, although ROMS presents lower salinities north of $43^{\circ} \mathrm{N}$

25 and south of $37^{\circ} \mathrm{N}$ (roughly differences of -0.1) and lower temperatures of about 
$1-0.5^{\circ} \mathrm{C}$ to the north, reaching $1^{\circ} \mathrm{C}$ to the south. At depth, both the ENACW and the

2 MW signatures are clearly observed, the former at 400-600 m with typical

3 salinities of 35.6-35.7 and the latter centered at 1000-1200 m with maximum

4 salinities of $35.2-35.3$ and a temperature of $11^{\circ} \mathrm{C}$.

\section{$6 \quad 3.3$ Mean Flow Structure}

8 The main focus of this section is the analysis of the circulation in the WIM

9 resulting from the process of adjustment of the hydrographical fields. Horizontal

10 slices at 50 and $1000 \mathrm{~m}$ depth showing monthly means for years 10 to 14 of the

11 SD run of the salinity and velocity fields for January and July are displayed in

12 Figure 9. In addition, vertical slices of the alongshore circulation at $43^{\circ} \mathrm{N}$ are

13 displayed in Figure 10, also for January and July monthly means.

15 a. Winter Circulation

16 One of the main dynamical features at the western Gulf of Cadiz is the presence

17 of a permanent cyclonic circulation ( $C 1$ in Figure 9b), which is part of the

18 structure usually referred to a topographic $\beta$-plume circulation (Kida et al.,

19 2008). Lamas et al. (2010) provided observational evidence of the structure. This

20 cyclonic vortex is stronger at the surface, but has a clear signature at depth as

21 well (Figure $9 \mathrm{a}, \mathrm{b})$.

22 The circulation in the WIM is affected by the entrance of the MW vein at the

23 gateway between Cape St Vincent and the Gorringe Bank; furthermore, along its

24 path around the WIM, the current sometimes becomes unstable and separates 
1 from the slope at different locations, generating recurrent anticyclonic structures

2 (Meddies) (Zenk and Armi, 1990).

3 As consequence of the spreading process of the MW vein, when the flow turns

4 into the Tagus Basin, the resulting mean flow is observed to generate mean

5 vorticity structures, two of them (anticyclonic and cyclonic) trapped on the

6 slope, denoted by A1 and C2 in Figure 9b, and an anticyclonic mean structure

7 offshore, denoted by A2. The resulting mean circulation is rather complex in the

8 Tagus basin, and on its northern side, near the Estremadura promontory in

9 progress in the poleward direction, giving rise to a partial detachment and an

10 anticyclonic structure, denoted A3, which extends from the MW levels up to the

11 surface (Figure 9a).

12 Evidences in the literature of this conspicuous negative vorticity in this region

13 are discussed by Daniault et al. (1994) and Mazé et al. (1997). On the other hand,

14 a region of anticyclonic vorticity is frequently observed near $40^{\circ} \mathrm{N}$ in the SST

15 field, separating the southern waters (warmer and saltier) that progress in the

16 poleward direction, from the northern waters (fresher and colder). Also, a

17 detailed discussion of this anticyclonic region in the framework of the dynamics

18 of the IPC is presented by Peliz et al. $(2003,2005)$.

19 On the northern side of anticyclone A3, a flow bifurcation is observed (Figure

20 9b). Part of the flow veers cyclonically and becomes part of a northwestward

21 flow that leaves the domain at $42^{\circ} \mathrm{N}, 12^{\circ} \mathrm{W}$ south of the Galicia Bank; the other

22 part of the flow reattaches to the slope in the poleward direction, along Cape

23 Finisterre at $43^{\circ} \mathrm{N}$. The vertical structure of this poleward flow at this latitude

24 can be seen in Figure 10a, consisting in a poleward flow, associated with a

25 downward slope of the isopycnal field centered at about $10^{\circ} \mathrm{W}$ and extending in 
1 the vertical direction from the levels of MW up to the surface, while offshore ef

$210^{\circ} \mathrm{W}$ a weak equatorward flow is dominant.

3 The $43^{\circ} \mathrm{N}$ section in the work of Mazé et al. (1997) shows similar circulation,

4 with poleward tendency maximum at $\sim 9.75^{\circ} \mathrm{W}$, and equatorward flow from

$510.5^{\circ} \mathrm{W}$ to $12^{\circ} \mathrm{W}$, which is attributed in part to the recirculation around the

6 Galicia Bank.

7 The circulation at $50 \mathrm{~m}$ (Figure 9a) shows patterns similar to those at $1000 \mathrm{~m}$,

8 showing coupling between the MW and the surface layers as further discussed

9 below.

11 b. Summer Circulation

12 The summer circulation at the MW levels (Figure 9d) presents a similar general

13 behavior to that of winter, discussed above. The inflow in the Tagus Basin occurs

14 closer to the slope than in January.

15 The anticyclonic structure centered at $40^{\circ} \mathrm{N}, 11^{\circ} \mathrm{W}$ exhibits a weaker signature

16 than the one observed in winter, which means a weaker tendency to detach from

17 the northern flank of the Estremadura Promontory, and hence stronger slope-

18 trapped flow at the levels of the MW.

19 One of the most striking features in our modeled mean circulation for summer is

20 the existence of conspicuous poleward flow. This issue will be further discussed

21 below. Concerning the surface layers circulation (Figure 9c), a band of

22 equatorward flow along the continental shelf/upper slope is observed associated

23 with the upwelling front, with particular notice of the velocities between Cape

24 Ortegal and Cape Finisterre. This flow is clearly visible in the vertical section at

$2543^{\circ} \mathrm{N}$, showing the structure of the upwelling front and an alongshore jet 
1 penetrating to a depth of about $400 \mathrm{~m}$ surrounded offshore by the poleward flow

2 centered at about $10^{\circ} \mathrm{W}$, and again equatorward weak flow offshore in a similar

3 way to the winter situation (Figure 10a)

4

5 c. Meridional Transport

6 In order to get some insight about the seasonal and interannual variability of the

7 circulation, series of alongshore transport were computed across three zonal

8 sections at latitudes $43^{\circ} \mathrm{N}, 40^{\circ} \mathrm{N}$ and $37.5^{\circ} \mathrm{N}$, and integrated in the upper $1500 \mathrm{~m}$

9 depth range.

10 Each zonal section is divided into 3 sub-sections (hereafter called boxes for

11 simplicity): shelf/upper slope (from the coast to the $400 \mathrm{~m}$ isobath), lower slope

12 and offshore box. These boxes will hereafter be designated as onshore, central

13 and offshore boxes, respectively. The width of the boxes is defined individually

14 for each latitude, because the location of both the upper and lower slope

15 circulation varies with latitude. The border of the onshore box was designed to

16 accommodate the shelf/upper slope circulation, and was therefore defined by

17 setting the depth at the $400 \mathrm{~m}$ isobath. The separation between the central and

18 the offshore boxes was specified by defining the central box, as the area of

19 prevailing poleward flow.

20 Thus, monthly means of meridional net transport, with positive (negative) values

21 corresponding to poleward (equatorward) flow, are shown for $43^{\circ} \mathrm{N}$ (Figure $11 \mathrm{a}-$

22 c), $40^{\circ} \mathrm{N}$ (Figure $11 \mathrm{e}-\mathrm{g}$ ) and $37.5^{\circ} \mathrm{N}$ (Figure $11 \mathrm{i}-\mathrm{k}$ ).

23 In the onshore boxes (Figure $11 \mathrm{c}, \mathrm{g}, \mathrm{k}$ ), the main feature observed is the

24 equatorward flow associated with upwelling, which presents one main peak

25 centered in July-August and occasionally one or several minor peaks during 
1 spring. In wintertime, a poleward flow associated with the inshore intrusion of

2 the IPC is observed on the upper slope. The equatorward summer transport peak

3 is typically $0.5 \mathrm{~Sv}$, independent of the latitude, but the spring peak varies from

4 less than $0.1 \mathrm{~Sv}$ to about $0.3 \mathrm{~Sv}$. Although a clear seasonal cycle of the circulation

5 is seen for both upwelling and poleward flow, there is also some interannual

6 variability in the structure of the peaks associated with the upwelling

7 equatorward transport, both in width and intensity. Regarding the seasonal

8 cycle, some differences can be observed in the equatorward circulation at

9 different latitudes. In the northern and central sections $\left(43^{\circ} \mathrm{N}\right.$ and $40^{\circ} \mathrm{N}$,

10 respectively - Figure 11c, g), the equatorward flow starts early in the year

11 (February) and lingers on until October, whereas in southern Portugal $\left(37.5^{\circ} \mathrm{N}-\right.$

12 Figure $11 \mathrm{k}$ ) a weak and variable circulation is observed during springtime

13 (February to May), and the clear signal of upwelling appears in June-July.

14 Furthermore, poleward flow along the shelf/upper slope is observed every year

15 for the $43^{\circ} \mathrm{N}$ and $40^{\circ} \mathrm{N}$ sections, with typical values of 0.2 to $0.3 \mathrm{~Sv}$, starting at the

16 beginning of autumn and with peaks in December, occasionally with secondary

17 peaks in January. The southern region does not show clear evidences of

18 poleward flow on the upper slope/shelf.

19 With respect to the central (Figure 11b, f, j) and offshore (Figure 11a, e, i) boxes,

20 the transport patterns are not as clearly defined as in the case of the onshore

21 box. For the northern and central latitudes $\left(43^{\circ} \mathrm{N}\right.$ and $\left.40^{\circ} \mathrm{N}\right)$ in the central box

22 (Figure 11b, f), two peaks of poleward flow are observed throughout the year in

23 almost all simulation years: the first one during summertime (July to

24 September), presenting high transport values, from 3 to $10 \mathrm{~Sv}$; the second peak

25 with smaller amplitudes, 2 to $7 \mathrm{~Sv}$, is observed from November to January. Both 
1 transport peaks show strong interannual variability. The first peak appears as an

2 offshore poleward flow co-existing with the inshore summer upwelling peak (cf.

3 Figure 11b with Figure 11c and Figure 11f with Figure 11g). This offshore

4 shifting of poleward flow during upwelling season has also been reported in

5 hydrographical cruises (Peliz et al., 2002, and Torres and Barton, 2007). The

6 second peak is associated with the winter IPC. Conversely, every year, recurrent

7 peaks of equatorward transport are observed during the late winter-spring

8 months. The southern region in the central box (Figure 11j) presents a complex

9 pattern, although the tendency for poleward flow with multiple peaks during

10 summer (shaded in Figure 11j), late autumn and January is still discernible. The

11 tendency for equatorward flow observed during late winter and spring is only

12 partially observed. Recall that this box is strongly influenced by the MW vein and

13 the corresponding shedding of meddies, which makes it more difficult to

14 interpret than the patterns described for the northern region.

15 The offshore region (Figure 11a, e, i) is the widest of the three boxes, and does

16 not present a clear seasonal pattern as in the central and onshore boxes. The

17 northern offshore box (Figure 11a) is characterized by a tendency for

18 equatorward flow, with typical values of less than $5 \mathrm{~Sv}$, as previously discussed

19 (Figure 10a, b). This behavior is opposite to the one observed at the central box

20 at the same latitude (Figure $11 \mathrm{~b}$ ), which means that at $43^{\circ} \mathrm{N}$ the poleward flow is

21 preferentially attached to the slope (central box), which Figure 9b, d also shows.

22 At $40^{\circ} \mathrm{N}$ (Figure 11e), the offshore box is characterized by high values of

23 transport in both directions, resulting from the anticyclonic vorticity structure of

24 the mean circulation (denoted A3 in Figure 9b). However, the net overall

25 transport in this box (Figure 11e) is poleward during the summer months with 
1 strong interannual variability, and on the other hand, presents also peaks of

2 poleward flow in February-March. This late winter poleward transport is

3 delayed by two to three months relative to the peaks observed in the central box

4 at $40^{\circ} \mathrm{N}$ (Figure 11f), which can be interpreted as the westward IPC migration.

5 On the other hand, the separation of the flow associated with A3 (Figure 9b)

6 occurring north of the Estremadura Promontory also explains the poleward

7 tendency in this offshore box.

8 The southern $\left(37.5^{\circ} \mathrm{N}\right)$ offshore region (Figure 11i) is affected by a strong

9 variability, consequence of the spreading of the MW vein and its mesoscale

10 features. However, like for the central offshore box (Figure 11e) some features

11 can be observed, as peaks of poleward flow during summertime (shaded), and

12 during November-January for most of the years, but also equatorward peaks

13 between February and June every year.

153.4 Influence of the MW in the WIM circulation

17 One unique oceanographic feature in this region is the presence of the MW and

18 its associated current patterns. Comparing the obtained circulation from a model

19 configuration where the MW spreading through the Strait of Gibraltar was

20 removed, with the base experiment, it is possible to get some insights into the

21 influence of the MW spreading on the circulation of the region, which is closely

22 linked to the density distribution at depth along WIM upper slope and to the 23 dynamics of Atlantic surface and Central Waters and associated mesoscale 24 activity. 
1 The January and July mean circulation and salinity fields at $50 \mathrm{~m}$ and $1000 \mathrm{~m}$ in

2 depth are displayed in Figure 12, like for Figure 7. Zonal sections of meridional

3 velocity were also computed along latitudes $43^{\circ} \mathrm{N}$ for January and July, like for

4 Figure 10, and are shown in Figure 13.

5

6 a. Winter circulation

7 The $1000 \mathrm{~m}$ current fields (Figure 12b) present lower velocities in this No

8 Mediterranean Water case (hereafter NMW) and there are less vorticity

9 structures in the mean flow when compared to the base case. Poleward flow

10 remains dominant at the surface and extends to $\sim 1000 \mathrm{~m}$ depth. The mean

11 cyclonic recirculation cell signature to the south nearly disappears, as it was

12 associated to the MW outflow. In the Tagus Basin there are no longer clear

13 evidences of a region of vorticity structures, as it was in the base case (A1, A2, C2

14 in Figure 9b). North of the Estremadura Promontory, anticyclonic vorticity of the

15 mean flow can still be observed, but is much weaker than in the base case, with

16 velocities decreasing from $10-15 \mathrm{~cm} \cdot \mathrm{s}^{-1}$ throughout the water column to $2-4 \mathrm{~cm} . \mathrm{s}^{-}$

17 , barely reaching the surface (Figure 13a). Concerning the salinity field, weak

18 horizontal gradients are observed at $1000 \mathrm{~m}$ depth, as expected due to the

19 absence of MW.

20 Near the surface (Figure 12a), the patterns of the mean velocity field are similar

21 to those at $1000 \mathrm{~m}$ depth with increased intensity. Poleward current is the

22 prevailing pattern, with a continuous mean flow from the Gulf of Cadiz

23 northwards, around Cape St Vincent and along the WIM. The surface poleward

24 flow proceeds along northwestern Iberia with evidence of two branches: one

25 narrow branch over the continental shelf (not visible in the base experiment), 
1 and another wider branch centered at about $10^{\circ} \mathrm{W}$, both along the slope and

2 extending eastwards into the Bay of Biscay with stronger intensity than in the

3 base case. This double flow is also visible in the zonal sections (Figure 13a).

4 A computation similar to the one depicted in Figure 11 was carried out (not

5 shown) and it further confirms the prevailing poleward flow in the continental

6 shelf/upper slope (onshore boxes). Additionally, the mean annual balance is

7 positive, that is, it surpasses the equatorward transport of upwelling.

8 Regarding the density distribution in depth near the upper slope (Figures 10 and

9 13), there is a greater tendency for downward slope in the case of NMW than in

10 the base experiment, which explains the strengthening of the poleward flow near

11 the shelf. This increase in downward slope was also observed in other regions

12 along the WIM (not shown). This stronger inshore poleward flow is also visible

13 in the salinity field at $50 \mathrm{~m}$ depth (Figure 12a), where the penetration of the 36

14 isohaline (marked in a thick contour) reaches farther north than in the base case,

15 which presents nearly-zonal isohalines.

17 b. Summer circulation

18 For July, the mean circulation patterns are similar to those of January, for both

1950 and $1000 \mathrm{~m}$ depths (Figure $12 \mathrm{c}-\mathrm{d}$ ), that is, there is a general weakening of the

20 recirculation regions and a poleward flow tendency along the slope of WIM, as

21 well as a farther northward penetration of the 36 isohaline. As for the meridional

22 velocity zonal sections (Figure 13b), we find that there is still the strong inshore

23 poleward flow ramification observed in winter, which restricts upwelling to a

24 thinner band on the continental shelf (less than $0.5^{\circ}$ from the coast) and 
1 therefore also at depth, allowing the associated equatorward flow to spread only

2 for the first $100-150 \mathrm{~m}$.

3 In this way, the main effect of the absence of the MW vein on the mean

4 circulation of WIM is the suppression or strong attenuation of a significant part

5 of the recirculating flow associated with the mesoscale features characteristic of

6 the MW spreading, such as shedding of meddies southwest of the Iberian

7 Peninsula, whose signature in the mean flow are the structures depicted in

8 Figure 9b, $\beta$-plume cyclonic circulation in the Gulf of Cadiz, anticyclonic vorticity

9 generation north of the Estremadura Promontory, and meandering along

10 northwestern Iberia. As a consequence, the poleward flow seems to circulate

11 more trapped to the slope, between $10^{\circ} \mathrm{W}$ and $9.5^{\circ} \mathrm{W}$.

13 4. Discussion

15 The circulation of the Western Iberian Margin was studied by means of a high-

16 resolution primitive-equation numerical model. It was intended to model the

17 seasonal cycle of the hydrographic fields, and to study the associated circulation,

18 resulting from the interaction of the three main phenomena: The upwelling, the

19 Iberian Poleward Current system and the Mediterranean water outflow.

20 The WIM ocean circulation is characterized by a complex oceanic system and it is

21 influenced by large-scale phenomena like the eastward extension of the Azores

22 Current, the structure of the meridional density gradient, or the less energetic

23 Portugal offshore equatorward current. It is also influenced by small-scale

24 localized phenomena like the exchange of waters through the Strait of Gibraltar, 
1 which spreads along the NE Atlantic. The river inflow also has influence on the

2 circulation in the surface layers along the continental shelf, and offshore.

3 The main focus of this study is to integrate the above mentioned phenomena into

4 a numerical configuration, that takes into account the large-scale phenomena

5 and the local phenomena referred to above. The main objective is to study the

6 mean hydrography and flow with special emphasis on the shelf/slope mean

7 circulation and transports, and its seasonal evolution. The connection between

8 the intermediate circulation (at the MW levels) with the surface layers is

9 explored, and the prevalence of poleward slope flow along the summer.

11 a. Circulation Considerations

12 The forcing that we used lacks nonseasonal transient forcing and contains no

13 interannual or synoptic meteorological scale variability. It was intended to model

14 the hydrographic fields, and to reach a realistic circulation as a result of the

15 adjustment of the hydrographic fields. Concerning this resulting circulation,

16 many of the modeled features have their correspondence in the available

17 observations. The main pattern of the circulation consists in a poleward flow

18 along the slope during winter, which lingers on in summer. In addition to the

19 classic ideas related in the introduction, Torres and Barton (2006) described a

20 complementary view of the initial development of the flow along northern WIP;

21 they estimated a mean transport of $2 \mathrm{~Sv}$ from the surface down to $500 \mathrm{~m}$ and

22 postulated that the poleward flow could penetrate down to the levels of MW. The

23 authors hypothesize that a poleward flow at the MW levels would arise from

24 different dynamical reasons, but can form a continuous flow inducing

25 topographic guidance of the surface flow. This behavior is well reproduced by 
1 the model results, suggesting that the poleward flow extends down to the levels

2 of the MW (Figure $12 \mathrm{a}-\mathrm{b})$.

3 The winter flow patterns obtained by the SD configuration resemble the typical

4 description of poleward flow in the literature. The model results, as seen by the

5 analyzed boxes (Figure 11), also suggest interannual variability associated with

6 the intrinsic variability, and hence not resulting from external forcing.

7 However, this resulting interannual variability does not explain episodes of

8 strong alongshore current observed in particular years only (January 1990,

9 1996, 1998 as reported in García-Soto et al., 2002, and Peliz et al., 2005). This

10 means that factors other than climatological forcing or large-scale forcing, both

11 imposed seasonally but with no interannual variability, may explain the

12 variability and the years of extreme poleward flow, not described within our

13 simulations.

14 When considering the mean fields of hydrographic properties and alongshore

15 velocity fields for several years, we obtain a picture of a poleward flow extending

16 from the surface down to the levels of the MW, centered at about $10^{\circ} \mathrm{W}$, with

17 weak vertical shear and typical velocities of 6 to $10 \mathrm{~cm} . \mathrm{s}^{-1}$ for winter and

18 summer, although with some weakening at the surface in this season (Figure 10).

19 This coupling between the MW and the Central Water layers was already

20 suggested by Mazé et al. (1997). Moreover, observations of Huthnance et al.

21 (2002) report maximum poleward flow at moorings near $42^{\circ} \mathrm{N}, 9.5^{\circ} \mathrm{W}$ in

22 September-October for all depths, a secondary peak in December-January for the

23 uppermost currentmeter, and a maximum of equatorward flow in February-

24 April. These features resemble the transport patterns in the central box for

25 section $43^{\circ} \mathrm{N}$ (Figure 11b). Likewise, persistent poleward flow at about $250 \mathrm{~m}$ 
1 depth at a location near $42.3^{\circ} \mathrm{N}, 10.2^{\circ} \mathrm{W}$ is reported by Peliz et al. (2005) based

2 on datasets of the Instituto Español de Oceanografía (Alonso et al., 1995), where

3 the intensity of the poleward current was about $10 \mathrm{~cm} \cdot \mathrm{s}^{-1}$ and no correlation

4 between winds and currents was found at this mooring. This tendency for

5 poleward flow at this longitude is comparable to the mean values presented in

6 Figure 10.

7 Concerning the issue related to the presence of poleward flow during the

8 upwelling season, Peliz et al. (2002) presented evidences of such behavior for

9 central Portugal. Torres and Barton (2007) studied the Galician shelf/slope

10 based on hydrography and ADCP measurements and also showed the

11 coexistence of offshore poleward flow during June 1997 at the start of the

12 upwelling season. The model results suggest that poleward flow is present along

13 the slope and coexist with the upwelling-associated flow along the shelf/upper

14 slope. This is visible not only in the mean alongshore velocities, but also in the

15 transport associated with the central (slope) box (Figure 11).

17 b. The influence of the MW flow on WIM

18 Concerning the experiment without explicit Mediterranean Water exchange at

19 the Strait of Gibraltar, the resulting circulation consists in a general tendency for

20 poleward currents in way similar to the SD experiment, which flows mainly

21 trapped on the slope. The tendency for poleward flow regardless of the presence

22 or absence of Mediterranean Water seems to be a robust result. However, the

23 MW vein and its mesoscale features have strong influence on the poleward flow

24 paths along the WIM, namely the enhancement of the separation north of Cape St

25 Vincent, the promotion of strong anticyclonic recirculation north of the 
1 Estremadura Promontory and the separation at $41-42^{\circ} \mathrm{N}$. The enhancement of

2 the slope-trapped poleward flow is a noteworthy result given that one would

3 expect the reverse by switching off the MW flow. There are a few possible

4 reasons for this effect in the absence of MW spreading: i) the absence of the

5 associated positive thermohaline anomaly of the MW at mid-depths forces the

6 density distribution at depth to re-arrange, so that the geostrophic adjustment at

7 the slope, seen as a downward inflection of isopycnals, takes place at upper

8 levels, as referred to above. As discussed in Huthnance (1984), geostrophic

9 adjustment at western coasts produces the so-called Eastern Boundary Currents,

10 which flow usually in subsurface in a direction opposite to that of the prevailing

11 winds; ii) the almost disappearance of the cyclonic recirculation in the Gulf of

12 Cadiz, the absence of detached anticyclonic structures throughout the WIM

13 (meddies), and the absence of instabilities (meanders) associated with the

14 absence of the MW vein, may allow a stronger slope-trapped poleward flow that

15 would otherwise spread offshore, and at once a more stable flow along the WIM

16 as it is observed in SD domain under NMW (No Mediterranean Water)

17 experiment. Consequently, lower levels of EKE were observed in the case of

18 NMW (not shown); iii) several authors (e.g. Jia, 2000; Kida et al., 2008; Volkov

19 and $\mathrm{Fu}, 2010$ ) have hypothesized that there is a connection between the MW

20 outflow in the Gulf of Cadiz and the recirculation of the Azores Current

21 southwest of the Iberian Peninsula, and even the very existence of that current.

22 Therefore, the removal of the MW flow into the Atlantic may have implications at

23 a larger spatial scale, which would then produce changes on the structure and

24 intensity of the poleward flow. However, we cannot draw conclusions on this

25 matter since our target domain (SD) does not enclose the Azores Current region. 
1 The results suggest that in order to be able to realistically model the WIM

2 circulation, a good representation of the MW spreading should be achieved,

3 including its associated mesoscale features that control the low frequency

4 circulation.

6 5. Conclusions

8 A numerical configuration was setup to resolve the ocean circulation at the

9 Western Iberian Margin, based on climatological forcing, in order to study the

10 resulting dynamical features of the surface layers down to the Mediterranean

11 Water levels.

12 As a first step, the hydrographic fields resulting from the equilibrium solution

13 were analyzed and compared to climatological values, and we obtained

14 reasonable results that allow exploring the associated circulation and studying of

15 the mean seasonal velocity fields and associated transports.

16 The resulting circulation presents a tendency for poleward flow along the slope

17 of the WIM, but also evidences of equatorward flow mostly in spring. Also, as

18 expected, wind-forced upwelling-driven equatorward flow is observed along the

19 continental shelf in summer, in coexistence with poleward flow offshore. The

20 main paths of poleward flow appear to be linked to the MW vein along the WIM.

21 A schematic view of the annual circulation at $1000 \mathrm{~m}$ (which extends its main

22 features up to the surface layers), showing the main paths of the mean

23 circulation, is proposed in Figure 14.

24 The MW vein enters through the Cape St Vincent-Gorringe Bank gateway and

25 flows in the northwestward direction, separating from the southwestern slope of 
1 the Iberian Peninsula (near cape St Vincent) through an anticyclonic mean

2 vorticity region (A1). Part of the flow continues poleward along the slope and

3 part recirculates southward through a cyclonic mean vorticity region (C2) and

4 continues poleward offshore due to the presence of another anticyclonic

5 structure (A2). Both poleward branches, at the slope and offshore, give rise to

6 the A3 anticyclonic region north of the Estremadura Promontory, although there

7 is still flow along the slope, getting around the promontory. On the northern

8 flank of this mean vorticity region, results suggest a new separation: part of the

9 flow returns toward the coast and continues as the slope poleward flow, which is

10 linked to the so-called Iberian Poleward Current (IPC); the other part circulates

11 poleward in another offshore branch between $11^{\circ} \mathrm{W}$ and $12^{\circ} \mathrm{W}$. The slope

12 poleward flow seems to separate south of $42^{\circ} \mathrm{N}$ and joins the offshore branch,

13 exiting afterwards the domain south of the Galicia Bank. The slope branch

14 continues to flow northward along Cape Finisterre, with evidences of a

15 separation at the northwestern tip of the Iberian Peninsula. Observational

16 evidences for many of the features of this scheme can be found in the literature,

17 as discussed above.

20 Acknowledgments

22 The FCT (Fundação para a Ciência e Tecnologia) provided a PhD grant to A.C.P

23 (SFRH/BD/47500/2008). This work is part of the 'ISCAD - Inner shelf circulation

24 and dispersion patterns: Interactions with estuarine systems",

25 PTDC/MAR/65760/2006 research project, also funded by the FCT under the 
1 European Regional Development Fund. This paper is also a contribution to

2 CAIBEX project (CTM2007-66408-C02) (Spanish Ministry of Education and

3 Science), and to RAIA project (0313_RAIA_1_E) funded by POCTEP and FEDER,

4 that supported N.C. grant.

5

6

7 References

8

9 Alonso, J., F.F. de Castillejo, G. Diaz del Rio, D. Marcote, and G. Casas (1995),

10 Preliminary Results of Current Measurements in the North West of the Iberian

11 Peninsula, MORENA Sci. and Tech. Rep. no 15, Instituto Espanol de Oceanografia

12 C.0., La Coruna, Spain.

13

14 Álvarez-Salgado, X.A., F.G. Figueiras, F.F. Pérez, S. Groom, E. Nogueira, A.V.

15 Borges, L. Chou, C.G. Castro, G. Moncoiffé, A.F. Ríos, A.E.J. Miller, M. Frankignoulle,

16 G. Savidge, and R. Wollast (2003), The Portugal coastal counter current off NW

17 Spain: new insights on its biogeochemical variability, Prog. in Oceanog., 56, 2,

18 281-321, doi: 10.1016/S0079-6611(03)00007-7.

19

20 Amante, C., and B.W. Eakins (2009), ETOP01 1 Arc-Minute Global Relief Model:

21 Procedures, Data Sources and Analysis. NOAA Tech. Memorandum NESDIS

22 NGDC-24, 19 pp.

24 Ambar, I., and M.R. Howe (1979), Observations of the Mediterranean outflow I -

25 Mixing in the Mediterranean outflow, Deep-Sea Res. Part A, 26, 5, 535-554. 
2 Antonov, J. I., D. Seidov, T. P. Boyer, R. A. Locarnini, A. V. Mishonov, H. E. Garcia, 0.

3 K. Baranova, M. M. Zweng, and D. R. Johnson, 2010. World Ocean Atlas 2009,

4 Volume 2: Salinity. S. Levitus, Ed. NOAA Atlas NESDIS 69, U.S. Government

5 Printing Office, Washington, D.C., $184 \mathrm{pp}$

6

7 Barja, F.J.R, and F.R. Lestegás (1992), Os Ríos Galegos - Morfoloxía e Réxime,

8 Consello da Cultura Galega, Ponencia de Patrimonio Natural, Santiago de

9 Compostela, Spain.

11 Batteen, M.L., J.R. Martinez, D.W. Bryan, and E.J. Buch (2000), A modeling study of

12 the coastal eastern boundary current system off Iberia and Morocco, J Geophys

13 Res-Oceans, 105 (C6), 14173-14195.

14

15 Batteen, M.L., A.S. Martinho, H.A. Miller, and J.L. McClean (2007), A process-

16 oriented modelling study of the coastal Canary and Iberian Current system, Oc.

17 Mod., 18, 1-36.

18

19 Bower, A.S., L. Armi, and I. Ambar (1995), Direct evidence of meddy formation off

20 the southwestern coast of Portugal, Deep-Sea Res. I, 42, 9, pp. 1621-1630.

22 Coelho, H.S., R.J.J. Neves, M. White, P.C. Leitão, and A.J. Santos (2002), A model for

23 ocean circulation on the Iberian coast, J. Mar. Sys., 32, 1-3, 153-179, 24 doi:10.1016/S0924-7963(02)00032-5. 
1 da Silva, A.M., C.C. Young, and S. Levitus (1994), Atlas of Surface Marine Data

2 1994. NOAA Atlas NESDIS 10. U.S. Department of Commerce, NOAA, NESDIS.

4 Daniault, N., J.P. Mazé, and M. Arhan (1994), Circulation and Mixing of

5 Mediterranean Water West of the Iberian Peninsula, Deep-Sea Res. I, 41, 11-12,

6 1685-1714, doi:10.1016/0967-0637(94)90068-X.

7

8 Fiúza A.F.G. (1984), Hidrologia e dinâmica das águas costeiras de Portugal, PhD

9 thesis, University of Lisbon, $294 \mathrm{pp}$.

11 Friocourt Y., B. Levier, S. Speich, B. Blanke, S. Drijfhout (2007). A regional

12 numerical ocean model of the circulation in the Bay of Biscay. J Geophys Res-

13 Oceans, 112, C09008, doi:10.1029/2006JC003935

15 Frouin, R., A.F.G. Fiúza, I. Ambar, and T.J. Boyd (1990), Observations of a

16 Poleward Surface Current off the coasts of Portugal and Spain during winter, J

17 Geophys Res-Oceans, 95 (C1), 679-691, doi:10.1029/JC095iC01p00679

19 García-Lafuente, J., J.C. Sánchez Garrido, G. Díaz del Río, F. Criado Aldeanueva, D.

20 Marcote, A. Sánchez Román, (2008), Low-frequency variability of the

21 Mediterranean undercurrent off Galicia, northwestern Iberian Peninsula, Journal

22 of Marine Systems, 74, 1-2, 351-363, doi:10.1016/j.jmarsys.2008.02.007

24 Garcia-Soto, C., Pingree, R.D., Valdés, L., 2002. Navidad development in the 25 southern Bay of Biscay: climate change and swoddy structure from remote 
1 sensing and in situ measurements. J Geophys Res-Oceans 107 (C8)

2 doi:10.1029/2001JC001012

3

4 Haidvogel, D.B., and A. Beckmann (1999), Numerical ocean circulation modeling,

5 Series on Environm. Sci. and Management, Vol.2, Imperial College Press.

6

7 Haynes, R., and E.D. Barton (1990), A poleward flow along the Atlantic coast of

8 the Iberian Peninsula, J Geophys Res-Oceans, 95 (C7), 11425-11441,

9 doi:0.1029/JC095iC07p11425.

11 Huthnance, J.M. (1984), Slope currents and "JEBAR", J Phys Oceanogr, 14, 79512810.

14 Huthnance, J.M., H.M. Van Aken, M. White, E.D. Barton, B. Le Cann, E. Ferreira 15 Coelho, E. Alvarez Fanjul, P. Miller, and J. Vitorino (2002), Ocean margin 16 exchange - water flux estimates, J Marine Syst, 32, 107-137.

18 Iorga, M.C., and M.S. Lozier (1999), Signatures of the Mediterranean outflow from

19 a North Atlantic climatology 1. Salinity and density fields, J Geophys Res-Oceans,

20104 (C11), 25985-26009 doi:10.1029/1999JC900115.

22 Jia, Y., 2000: Formation of an Azores Current Due to Mediterranean Overflow in a 23 Modeling Study of the North Atlantic. J. Phys. Oceanogr., 30, 2342-2358.

24 doi: http://dx.doi.org/10.1175/1520-0485(2000)030<2342:FOAACD>2.0.CO;2 25 
1 Kida, S., J.F. Price, and J. Yang (2008), The Upper-Oceanic Response to Overflows:

2 A Mechanism for the Azores Current. J. Phys. Oceanogr., 38, 880-895, doi:

3 10.1175/2007JP03750.1.

4

5 Lamas, L., Á. Peliz, I. Ambar, A. Barbosa Aguiar, N. Maximenko, and A. Teles-

6 Machado (2010), Evidence of time-mean cyclonic cell southwest of Iberian

7 Peninsula: The Mediterranean Outflow-driven $\beta$-plume?, Geophys Res Lett, 37,

8 L12606, doi:10.1029/2010GL043339.

10 Large, W.G., J.C. McWilliams, and S.C. Doney (1994), Oceanic vertical mixing: a 11 review and a model with a nonlocal boundary-layer parameterization, Rev. 12 Geophys., 32, 4, 363-403, doi:0.1029/94RG01872.

14 Locarnini, R. A., A. V. Mishonov, J. I. Antonov, T. P. Boyer, H. E. Garcia, O. K. 15 Baranova, M. M. Zweng, and D. R. Johnson, 2010. World Ocean Atlas 2009, 16 Volume 1: Temperature. S. Levitus, Ed. NOAA Atlas NESDIS 68, U.S. Government 17 Printing Office, Washington, D.C., 184 pp.

19 Marchesiello, P., J.C. McWilliams, and A. Shchepetkin (2001), Open boundary

20 conditions for long-term integration of regional oceanic models, Oc. Mod., 3, 1-2, 21 1-20, doi:10.1016/S1463-5003(00)00013-5.

23 Marchesiello P., L. Debreu, and X. Couvelard (2009), Spurious diapycnal mixing in 24 terrain-following coordinate models: the problem and a solution, Oc. Mod., 26, 325 4, 156-169, doi:10.1016/j.ocemod.2008.09.004. 
2 Mateus, M., Riflet, G., Chambel, P., Fernandes, L., Fernandes, R., Juliano, M.,

3 Campuzano, F., de Pablo, H., and Neves, R. 2012, An operational model for the

4 West Iberian coast: products and services, Ocean Sci., 8, 713-732.

5

6 Mazé, J.P., M. Arhan, and H. Mercier (1997), Volume budget of the eastern

7 boundary layer off the Iberian Peninsula, Deep-Sea Res. I, 44, 9-10, 1543-1574,

8 doi:10.1016/S0967-0637(97)00038-1.

9

10 Neshyba, S. (1986), Poleward flows along eastern ocean boundaries (ed.),

11 Springer-Verlag Publisher, ISBN 0387971750, 374 p.

12

13 Otero P., M. Ruiz-Villarreal, and A. Peliz (2008), Variability of river plumes off

14 Northwest Iberia in response to wind events, J. Mar. Sys., 72, 1-4, 238-255,

15 doi:10.1016/j.jmarsys.2007.05.016.

16

17 Paillet, J., M. Arhan, and M.S. McCartney (1998), Spreading of Labrador Sea Water

18 in the eastern North Atlantic, J Geophys Res-Oceans, 103 (C5), 10223-10239,

19 doi:10.1029/98JC00262.

20

21 Peliz, A., T.L. Rosa, A.M.P. Santos, and J.L. Pissarra (2002), Fronts, jets, and

22 counter-flows in the Western Iberian upwelling system, J. Mar. Sys., 35, 61-77,

23 doi:10.1016/S0924-7963(02)00076-3.

24 
1 Peliz, A., J. Dubert, D.B. Haidvogel, and B. Le Cann (2003), Generation and

2 unstable evolution of a density-driven Eastern Poleward Current: The Iberian

3 Poleward Current, J Geophys Res-Oceans, 108 (C8), 3268,

4 doi:10.1029/2002JC001443.

5

6 Peliz, A., J. Dubert, A.M.P. Santos, P.B. Oliveira, and B. Le Cann (2005), Winter

7 upper ocean circulation in the Western Iberian Basin-Fronts, Eddies and

8 Poleward Flows: an overview, Deep-Sea Res. I, 52, 4, 621-646,

9 doi:10.1016/j.dsr.2004.11.005.

11 Peliz, A., J. Dubert, P. Marchesiello, and A. Teles-Machado (2007), Surface

12 circulation in the Gulf of Cadiz: Model and mean flow structure, J Geophys Res-

13 Oceans, 112 (C11015), doi:10.1029/2007JC004159.

15 Peliz, A. Teles-Machado, P. Marchesiello, J. Dubert, J. Garcia Lafuente, 2009:

16 Filament generation off the Strait of Gibraltar in response to Gap winds,

17 Dynamics of Ocean and Atmosphere, 46, 36-45, doi: j.dynatmoce.2008.08.002

19 Penven, P., P. Marchesiello, L. Debreu, and J. Lefevre (2008), Software tools for

20 pre- and post-processing of oceanic regional simulations, Environm. Mod.

21 Software, 23, 5, 660-662, doi:10.1016/j.envsoft.2007.07.004.

23 Pingree, R.D., and B. Le Cann (1990), Structure, strength and seasonality of the

24 slope currents in the Bay of Biscay region, J. Mar. Biol. Ass. of the UK, 70, 857-

25 885, doi:10.1017/S0025315400059117. 
2 Relvas, P., E.D. Barton, J. Dubert, P.B. Oliveira, A. Peliz, J.C.B. da Silva, and A.M.P.

3 Santos (2007), Physical oceanography of the western Iberia ecosystem: Latest 4 views and challenges, Prog Oceanogr, 74, 2-3, 149-173, 5 doi:10.1016/j.pocean.2007.04.021.

6

7 Reynaud, T., P. Legrand, H. Mercier, and B. Barnier (1998), A new analysis of 8 hydrographic data in the Atlantic and its application to an inverse modeling 9 study, International WOCE Newsletters, 32, 29-31.

11 Richardson, P.L, A.S. Bower, W. Zenk, (2000) A census of Meddies tracked by

12 floats, Prog Oceanogr, 45, 2, 209-250.

14 Ríos, A.F., F.F. Pérez, and F. Fraga (1992), Water masses in the upper and middle 15 North Atlantic Ocean east of the Azores, Deep-Sea Res. I, 39, 3-4, 645-658, 16 doi:10.1016/0198-0149(92)90093-9.

18 Røed, L.P., and X.B. Shi (1999), A numerical study of the dynamics and energetics

19 of cool filaments, jets and eddies of the Iberian Peninsula, J Geophys Res-Oceans, 20104 (C12), 29817-29841, doi:10.1029/1999JC900175.

22 Saunders, P.M. (1982), Circulation in the eastern North Atlantic, J. Mar. Res., 40, $23 \quad 641-657$. 
1 Serra, N., I. Ambar, and D. Boutov (2010), Surface expression of Mediterranean

2 Water dipoles and their contribution to the shelf/slope - open ocean exchange,

3 Ocean Sci., 6, 191-209.

4

5 Shchepetkin, A.F., and J.C. McWilliams (2003), A method for computing

6 horizontal pressure-gradient force in an oceanic model with a non-aligned

7 vertical coordinate, J Geophys Res-Oceans, 108 (C3), 3090,

8 doi:10.1029/2001JC001047.

9

10 Shchepetkin, A.F., and J.C. McWilliams (2005), The regional oceanic modeling

11 system (ROMS): a split-explicit, free-surface, topography-following-coordinate

12 oceanic model, Oc. Mod., 9, 4, 347-404, doi:10.1016/j.ocemod.2004.08.002.

14 Sibuet, J.-C., S. Monti, B. Loubrieu, J.-P. Mazé, and S. Srivastava (2004), Carte 15 bathymétrique de l'Atlantique nord-est et du golfe de Gascogne: implications 16 cinématiques, Bulletin de la Société Géologique de France, 175, 5, 429-442.

18 Stevens, I., M. Hamann, J.A. Johnson, and A.F.G. Fiúza (2000), Comparisons

19 between a fine resolution model and observations in the Iberian shelf-slope

20 region, J. Mar. Sys., 26, 1, 53-74, doi:10.1016/S0924-7963(00)00038-5.

22 Torres, R., E.D. Barton, P. Miller, and E. Fanjul (2003), Spatial patterns of wind

23 and sea surface temperature in the Galician upwelling region, J Geophys Res-

24 Oceans, 108 (C4), 3130. doi:10.1029/2002JC001361 
1 Torres, R., and E.D. Barton (2006), Onset and development of the Iberian

2 poleward flow along the Galician coast, Continental Shelf Res., 26, 10, 1134-1153,

3 doi:10.1016/j.csr.2006.03.009.

4

5 Torres, R., and E.D. Barton (2007), Onset of the Iberian upwelling along the 6 Galician coast, Continental Shelf Res., 27, 13, 1759-1778, 7 doi:10.1016/j.csr.2007.02.005.

8

9 Troupin, C., F. Machín, M. Ouberdous, D. Sirjacobs, A. Barth, and J.-M. Beckers

10 (2010), High-resolution climatology of the northeast Atlantic using Data-

11 Interpolating Variational Analysis (Diva), J Geophys Res-Oceans, 115, C08005,

12 doi:10.1029/2009JC005512.

13

14 Veitch, J., P. Penven, and F. Shillington (2010), Modeling Equilibrium Dynamics of 15 the Benguela Current System. J. Phys. Oceanogr., 40, 1942-1964, doi: 16 10.1175/2010JP04382.1.

17

18 Volkov, Denis L., Lee-Lueng Fu, 2010: On the Reasons for the Formation and

19 Variability of the Azores Current. J. Phys. Oceanogr., 40, 2197-2220.

20

21 Zenk, W., and L. Armi (1990), The complex spreading pattern of Mediterranean

22 Water off the Portuguese continental slope, Deep-Sea Res. I, 37, 12, 1805-1823, 23 doi:10.1016/0198-0149(90)90079-B. 
1 Figure Captions:

3 Figure 1 - Map of the region under study: the first domain (FD), comprising the

4 Iberian Peninsula, the north of Africa (Morocco) and the Azores Islands; the local

5 domain (SD) marked with the main bathymetric and topographic features: Strait

6 of Gibraltar (SG), Cape St Vincent (CSV), Gorringe Bank (GoB), Estremadura

7 Promontory (EP), Iberian Abyssal Plain (IAP), Galicia Bank (GB), Cape Finisterre

8 (CF) and Cape Ortegal (CO). The stars mark the locations of analysis for section 93.2 .2$.

11 Figure 2 - A EKE comparison between altimetry (from AVISO) (top) and FD 12 output (bottom).

14 Figure 3 - Sea Surface Temperature (SST) in ${ }^{\circ} \mathrm{C}(\mathrm{a}-\mathrm{c})$ and Sea Surface Salinity 15 (SSS) (d-f) for January. (a, d) 5-year mean of ROMS output; (b, e) 7-year mean of 16 AVHRR at 02h and GHER-NEA climatology, respectively; (c, f) Difference 17 between (a) and (b) and between (d) and (e), respectively. Thick contours 18 outline null difference. The $200 \mathrm{~m}$ isobath is shown in thin black contour.

20 Figure 4 - Same as Figure 3 but for July.

22 Figure 5 - $\theta$-S diagrams monthly means of ROMS output (dashed lines, one per 23 year, for years 10 to 14) and GHER-NEA climatology (solid line) for January (a, 24 e), April (b, f), July (c, g) and October (d, h) for two regions: one centered at $38^{\circ} \mathrm{N}$, $2510^{\circ} \mathrm{W}(\mathrm{a}-\mathrm{d})$, the other centered at $42^{\circ} \mathrm{N}, 10^{\circ} \mathrm{W}(\mathrm{e}-\mathrm{h})$. Potential density anomaly 
$1\left(\sigma_{\theta}\right)$ is superimposed in dotted lines every $0.2 \mathrm{~kg} \mathrm{~m}^{-3}$; the shaded line

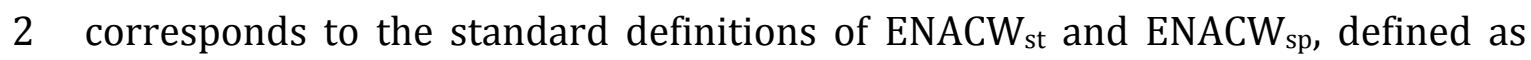

$3 \theta=10+8.462 *(S-35.4)$ for the subpolar branch $(34.8<S<35.7)$ and

$4 \theta=13.13+5.653 *(S-35.8)$ for the subtropical branch $(35.8<S<36.2)$, as defined by

5 Fiúza (1984).

6

7 Figure 6 - Zonal sections of temperature and salinity for January: (a, b) 5-year

8 means of ROMS output for $42^{\circ} \mathrm{N}$ and $38^{\circ} \mathrm{N}$, respectively; (c, d) GHER-NEA

9 climatology for $42^{\circ} \mathrm{N}$ and $38^{\circ} \mathrm{N}$, respectively. Sections are down to $1500 \mathrm{~m}$ and

10 the first $200 \mathrm{~m}$ are enlarged. Temperature is represented in black contours every

$110.5^{\circ} \mathrm{C}$ in the upper layers and every $1^{\circ} \mathrm{C}$ in the deeper layers. Salinity is depicted

12 in white contours every 0.1 and shades of gray for specific values: MW (35.9 to

13 36.3) is represented in light gray and ENACW (35.5 to 35.7) is represented in

14 dark gray. Bathymetry is colored in black.

16 Figure 7 - Same as Figure 6 but for July, except temperature in the upper layers

17 is represented in black contours every $1^{\circ} \mathrm{C}$.

19 Figure 8 - Meridional section of temperature and salinity at $11.5^{\circ} \mathrm{W}$, for January:

20 (a) 5-year means of ROMS output, (b) GHER-NEA climatology.

22 Figure 9 - Salinity and velocity fields for January (a, b) and July (c, d) at 50 m (a,

23 c) and at $1000 \mathrm{~m}$ (b, d). Isohalines are depicted every 0.2 (36 in thick black

24 contours) and the vector scale is indicated on the map. For information 25 regarding the pointing arrows, please refer to the text. 
2 Figure 10 - Zonal sections, at $43^{\circ} \mathrm{N}$, of 5 -year means of potential density

3 anomalies and meridional velocity for January (a) and July (b) down to $1500 \mathrm{~m}$

4 deep. $\sigma_{\ominus}$ is depicted every $0.2 \mathrm{~kg} \mathrm{~m}^{-3}$. The light shades of gray mark negative

5 values below -0.02 m.s. $\mathrm{s}^{-1}$ and the dark shades of gray positive values above 0.02

$6 \mathrm{~m} . \mathrm{s}^{-1}$. The thick contour is zero and the first $200 \mathrm{~m}$ are enlarged.

8 Figure 11 - Time series of meridional transport monthly means along: (a-d)

$943^{\circ} \mathrm{N}$; (e-h) $40^{\circ} \mathrm{N}$; and (i-l) $37.5^{\circ} \mathrm{N}$. Each column corresponds to a sub-section

10 represented in the rightmost column $(d, h, l)$. From left to right: (a, e, i) offshore;

11 (b, f, j) lower slope and adjacent upper layers; (c, g, k) shelf/upper slope (down

12 to $400 \mathrm{~m}$ ). Seasonal averages (July, August, September - JAS - and November,

13 December, January - NDJ) are plotted in shades of gray for northward and

14 southward transports. To the left of each plot, total northward and southward

15 averages are in black bars and the net average is in white bars.

17 Figure 12 - Salinity and velocity fields for January (a, b) and July (c, d) at $50 \mathrm{~m}(\mathrm{a}$,

18 c) and at $1000 \mathrm{~m}(\mathrm{~b}, \mathrm{~d})$ for the NMW run. Isohalines are depicted every 0.2 (36 in

19 thick black contours) and the vector scale is indicated on the map.

21 Figure 13 - Zonal sections, at $43^{\circ} \mathrm{N}$, of 5 -year means of potential density

22 anomalies and meridional velocity for the NMW run for January (a) and July (b)

23 down to $1500 \mathrm{~m}$ deep. $\sigma_{\ominus}$ is depicted every $0.2 \mathrm{~kg} \mathrm{~m}^{-3}$. The light shades of gray

24 mark negative values below $-0.02 \mathrm{~m} \cdot \mathrm{s}^{-1}$ and the dark shades of gray positive 
1 values above $0.02 \mathrm{~m} . \mathrm{s}^{-1}$. The thick contour is zero and the first $200 \mathrm{~m}$ are 2 enlarged.

3

4 Figure 14 - Schematic representation of the mean circulation at $1000 \mathrm{~m}$ as 5 obtained from the present numerical modeling study, showing the principal 6 paths of the obtained circulation structures, and the recirculation vorticity. 7 


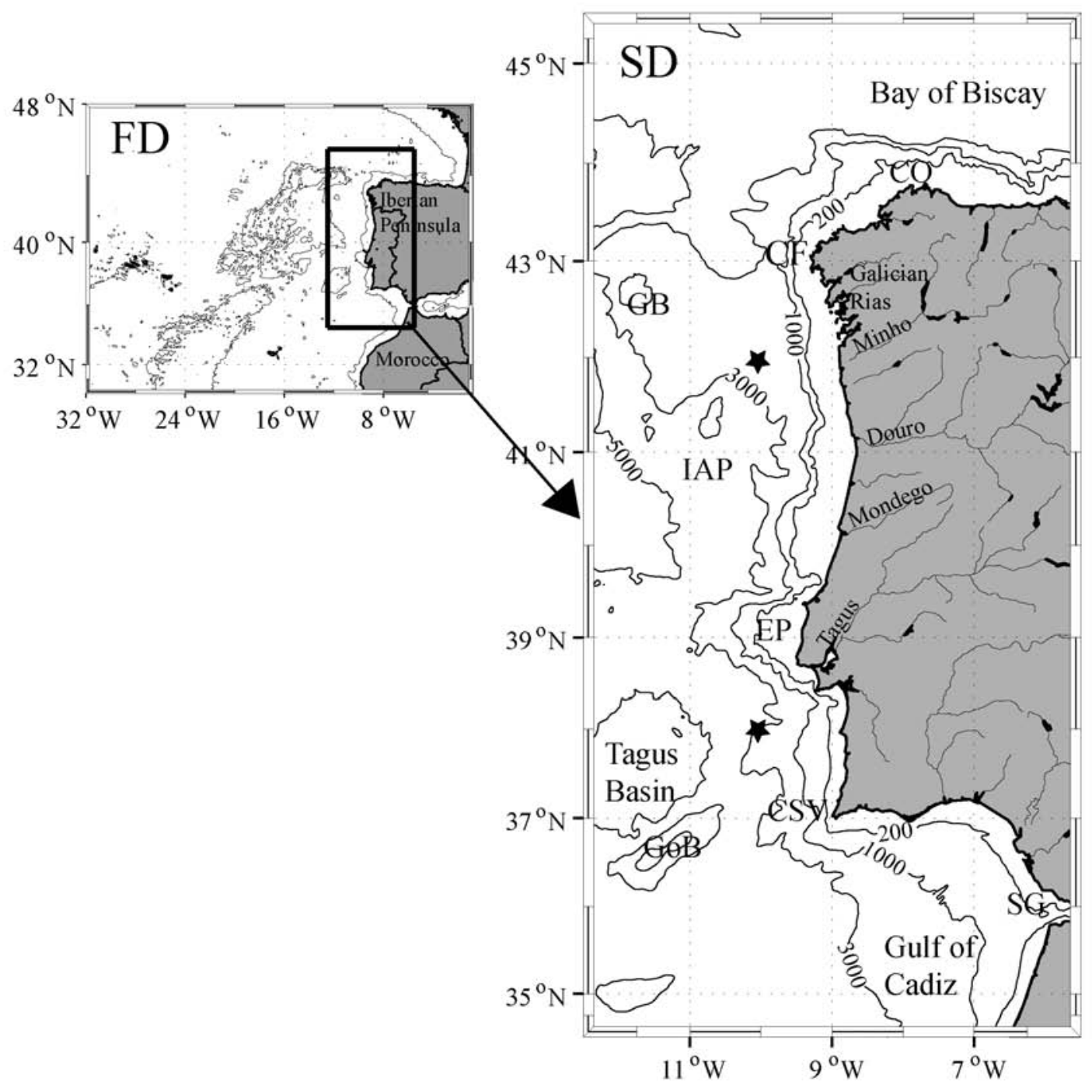

Figure 1 - Map of the region under study: the first domain (FD), comprising the Iberian Peninsula, the north of Africa (Morocco) and the Azores Islands; the local domain (LD) marked with the main bathymetric and topographic features: Strait of Gibraltar (SG), Cape St Vincent (CSV), Bank of Gorringe (GoB), Estremadura Promontory (EP), Iberian Abyssal Plain (IAP), Galicia Bank (GB), Cape Finisterre (CF) and Cape Ortegal (CO). The stars mark the locations of analysis for section 3.2.2. 


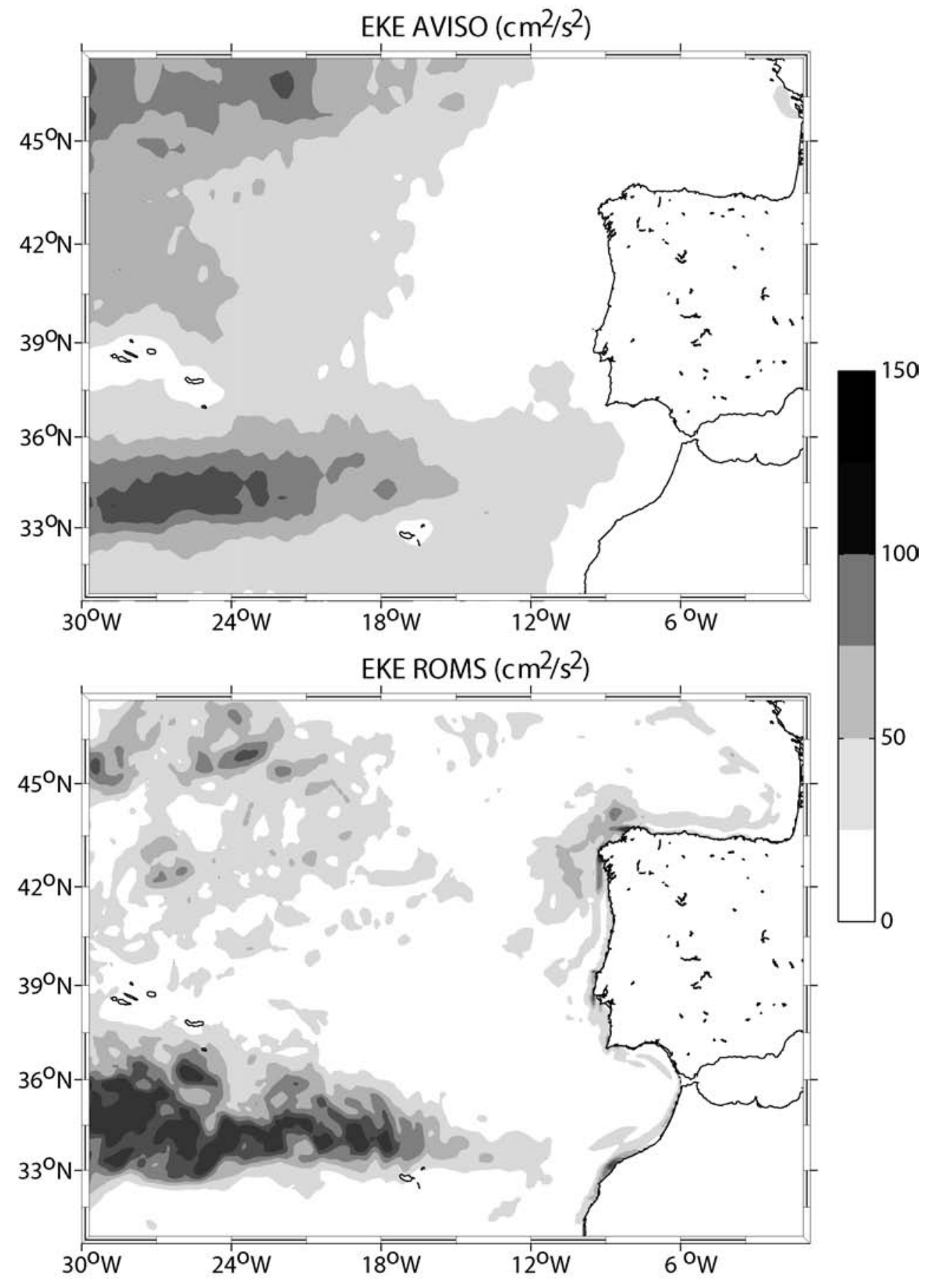

Figure 2 - A EKE comparison between altimetry (from AVISO) (top) and FD output (bottom). 


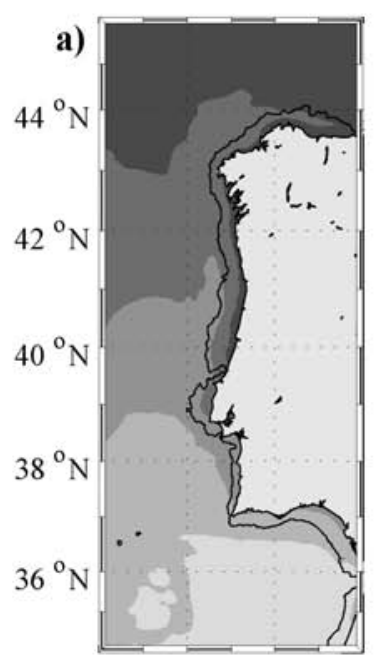

b)
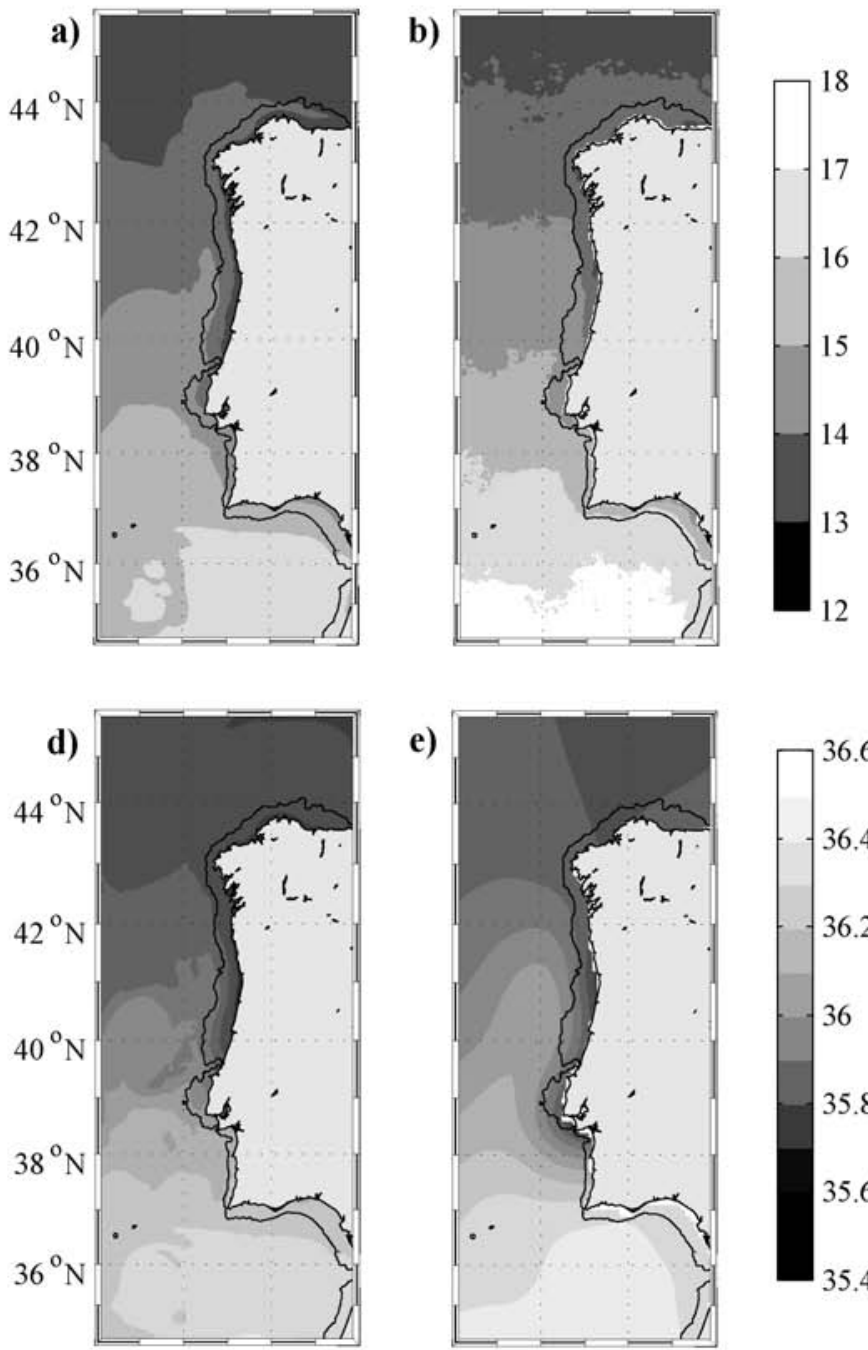

$12^{\circ} \mathrm{W} \quad 10^{\circ} \mathrm{W} \quad 8^{\circ} \mathrm{W} \quad 6^{\circ} \mathrm{W}$ e)

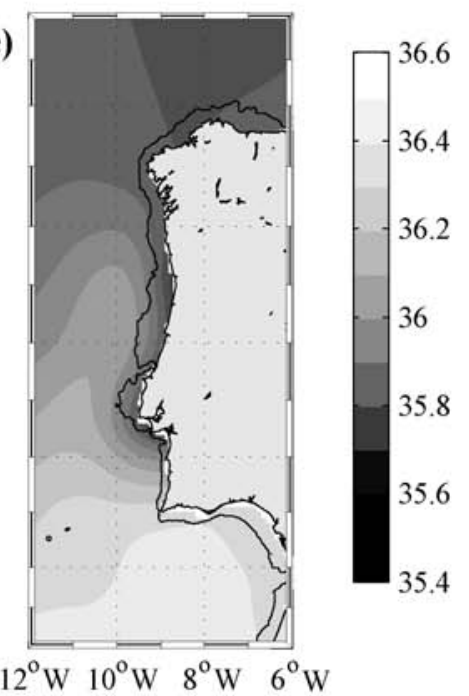

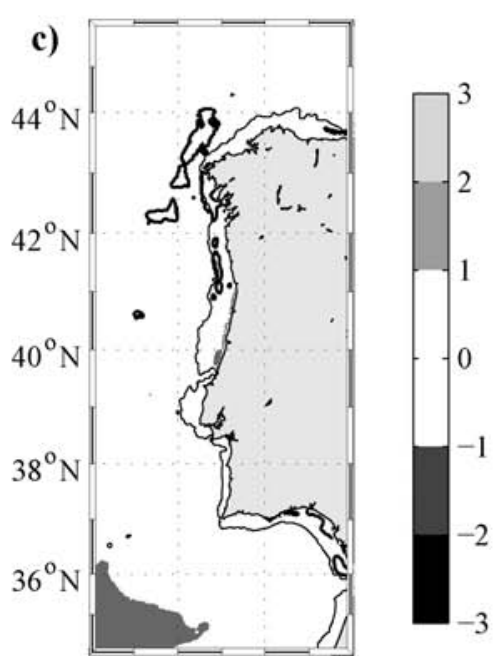

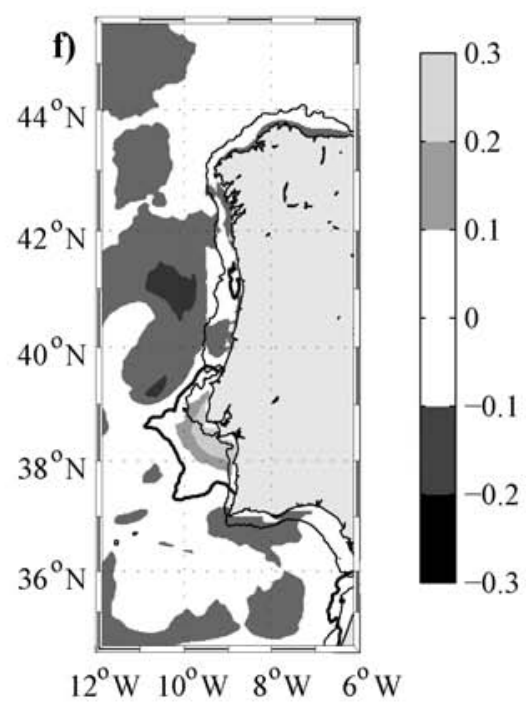

Figure 3 - Sea Surface Temperature (SST) in ${ }^{\circ} \mathrm{C}$ (a-c) and Sea Surface Salinity (SSS) (d-f) for January. (a, d) 5-year mean of ROMS output; (b, e) 7-year mean of AVHRR at $02 \mathrm{~h}$ and GHER-NEA climatology, respectively; (c, f) Difference between (a) and (b) and between (d) and (e), respectively. Thick contours outline null difference. The $200 \mathrm{~m}$ isobath is shown in thin black contour. 


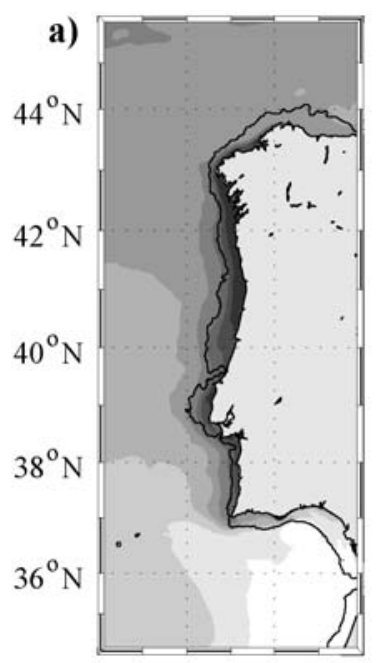

b)
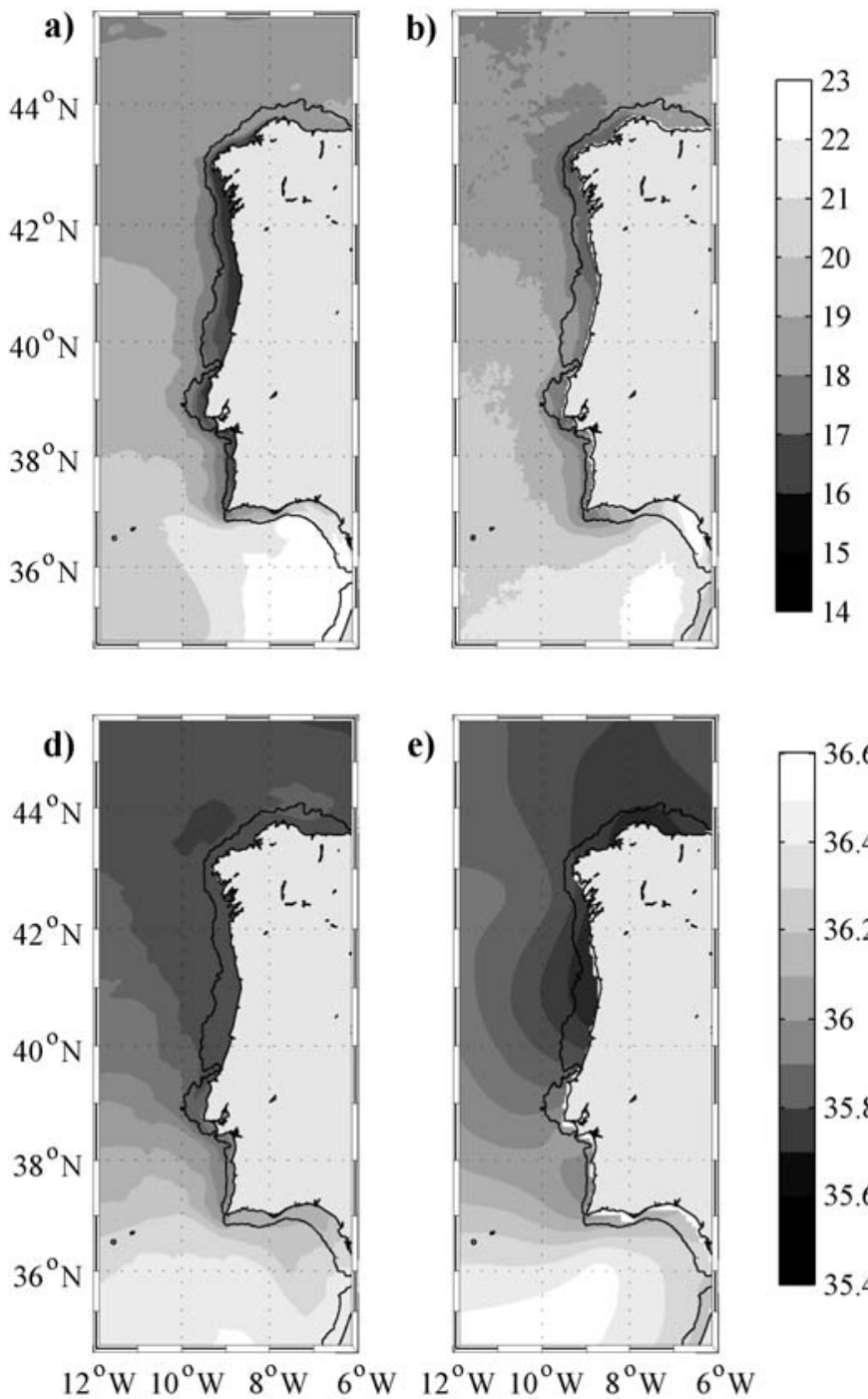

e)

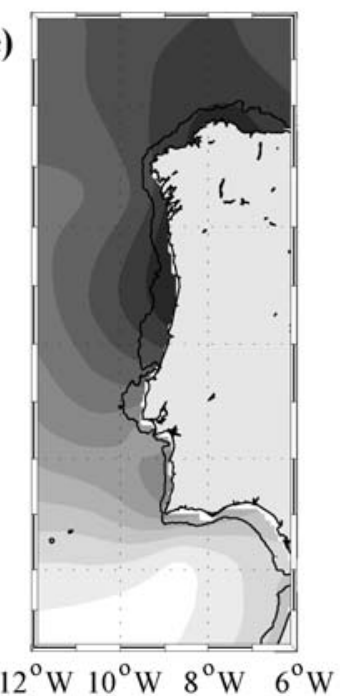

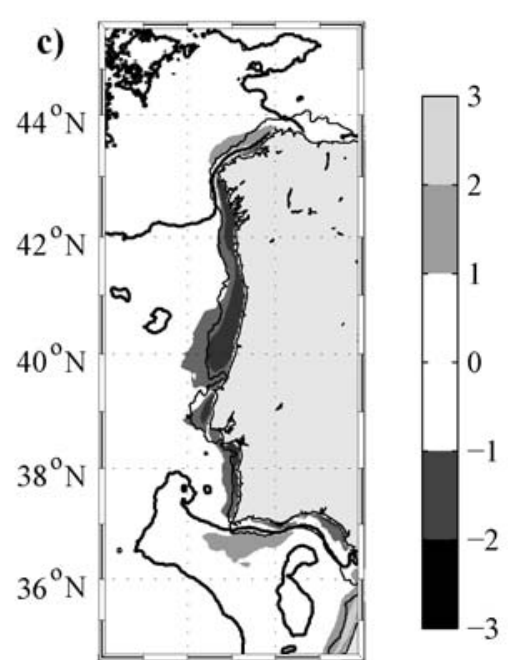

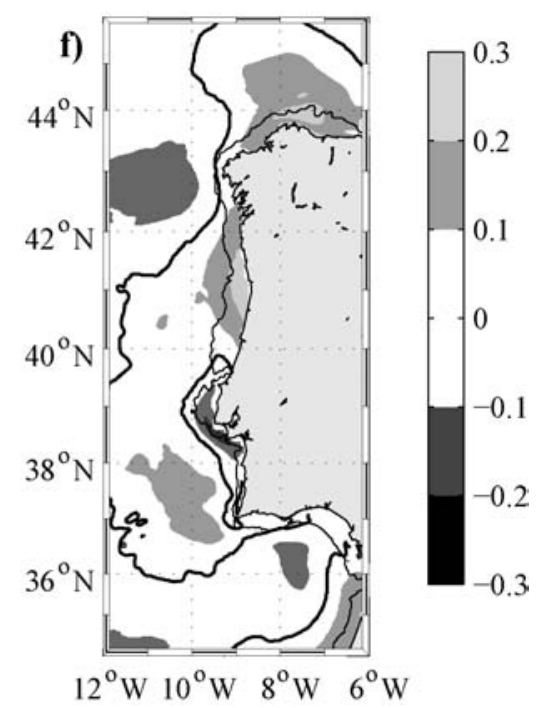

2 Figure 4 - Same as Figure 3 but for July. 
Jan
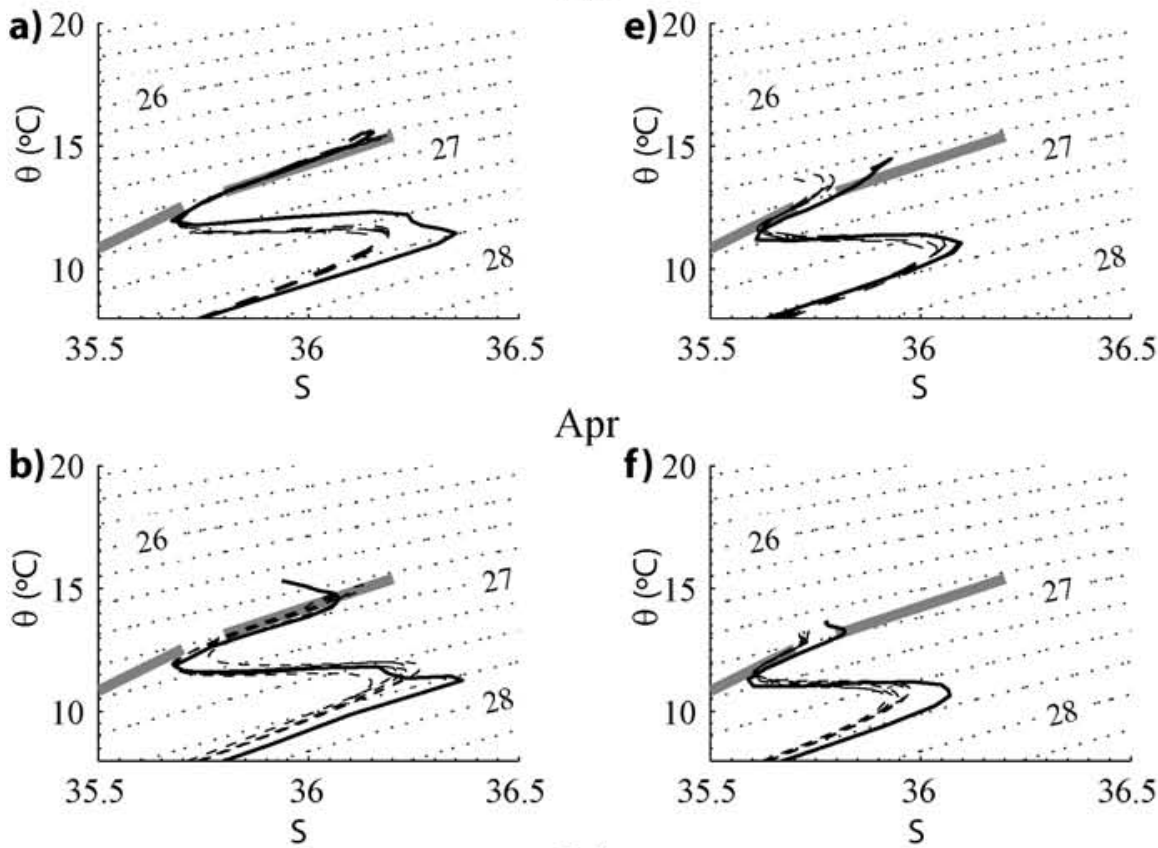

Apr

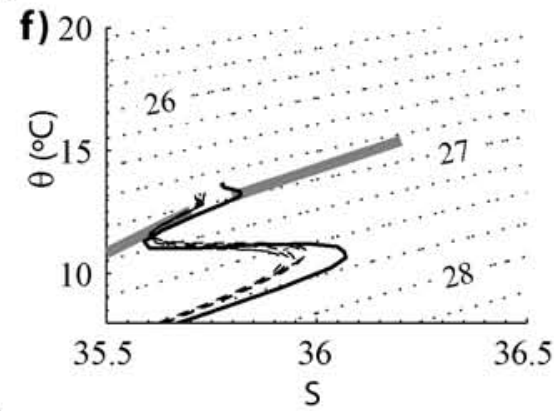

Jul
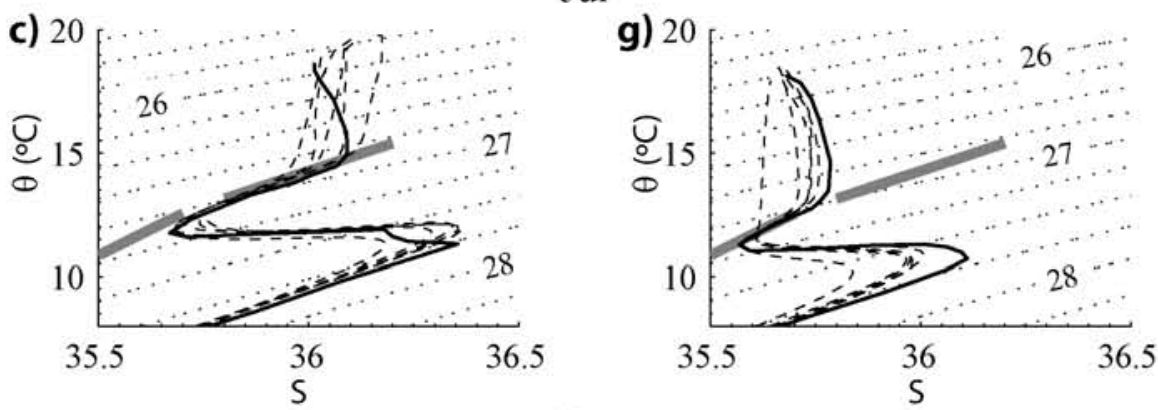

Oct
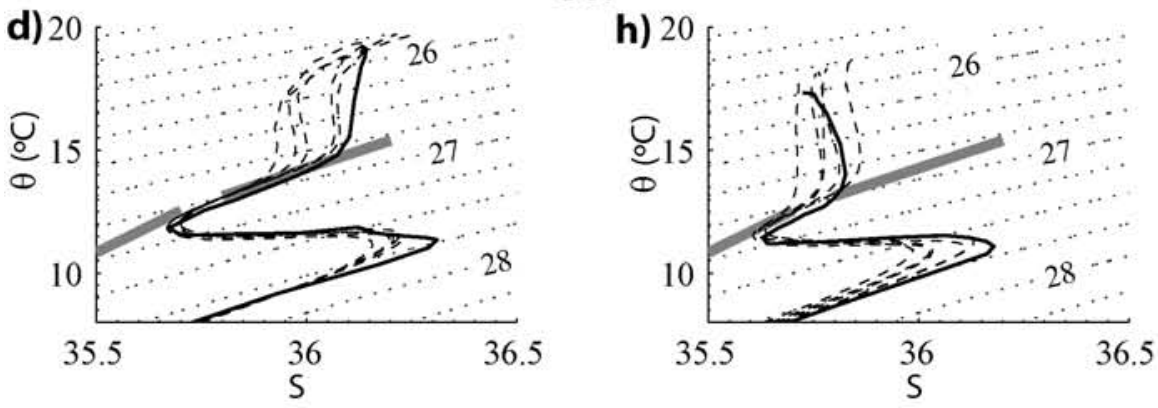

Figure $5-\theta$-S diagrams monthly means of ROMS output (dashed lines, one per year, for years 10 to 14) and GHER-NEA climatology (solid line) for January (a, e), April (b, f), July (c, g) and October (d, h) for two regions: one centered at $38^{\circ} \mathrm{N}, 10^{\circ} \mathrm{W}$ (a-d), the other centered at $42^{\circ} \mathrm{N}, 10^{\circ} \mathrm{W}$ (e-h).

Potential density anomaly $(\sigma \theta)$ is superimposed in pointed lines every $0.2 \mathrm{~kg} \mathrm{~m}^{-3}$; the shaded line corresponds to the standard definitions of

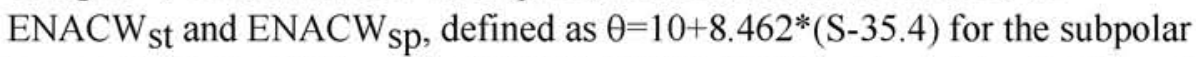
branch $(34.8<\mathrm{S}<35.7)$ and $\theta=13.13+5.653 *(\mathrm{~S}-35.8)$ for the subtropical branch $(35.8<\mathrm{S}<36.2)$, as defined by Fiúza [1984]. 

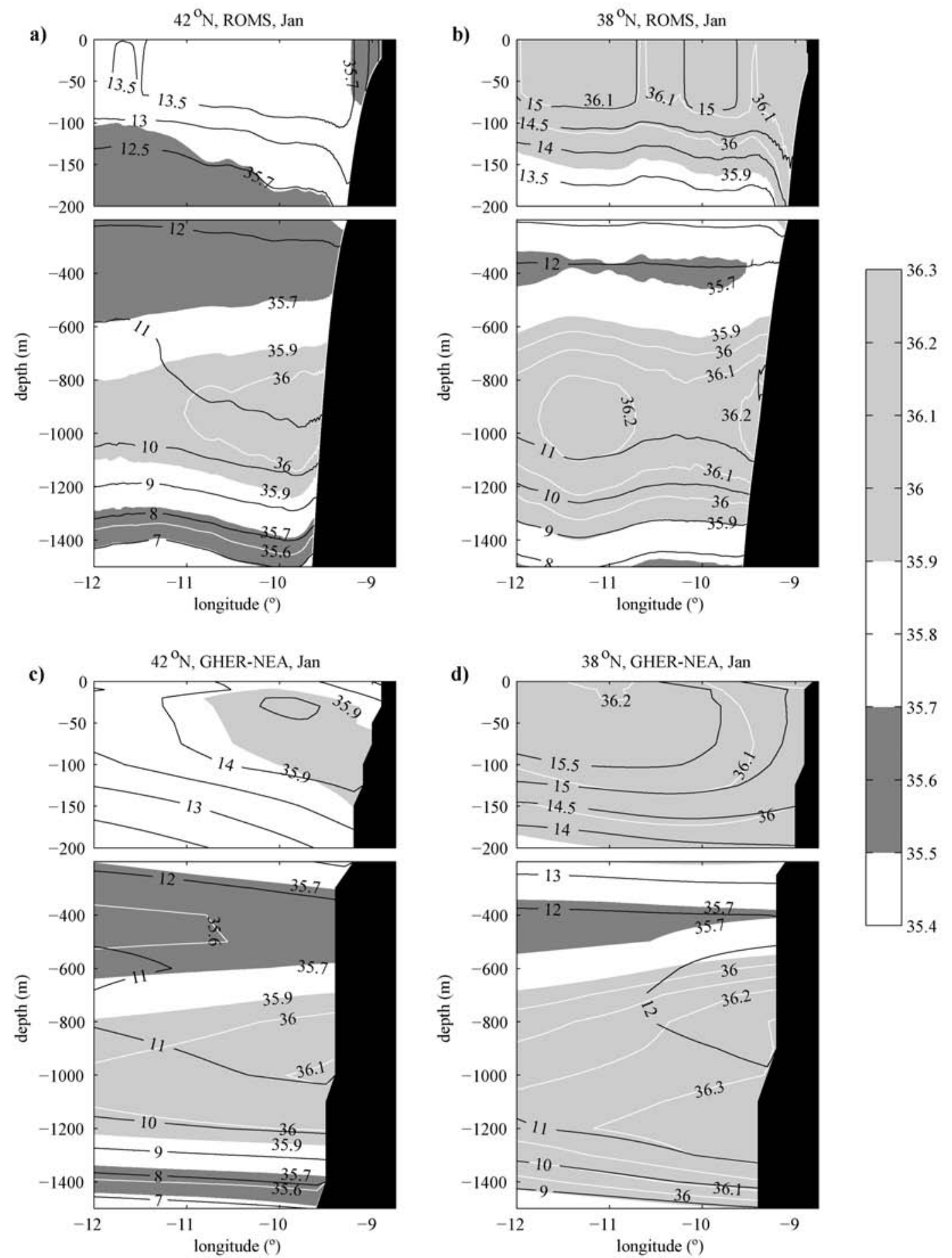

Figure 6 - Zonal sections of temperature and salinity for January: (a, b) 5-year means of ROMS output for $42^{\circ} \mathrm{N}$ and $38^{\circ} \mathrm{N}$, respectively; (c, d) GHER-NEA climatology for $42^{\circ} \mathrm{N}$ and $38^{\circ} \mathrm{N}$, respectively. Sections are down to $1500 \mathrm{~m}$ and the first $200 \mathrm{~m}$ are enlarged. Temperature is represented in black contours every $0.5^{\circ} \mathrm{C}$ in the upper layers and every $1^{\circ} \mathrm{C}$ in the deeper layers. Salinity is depicted in white contours every 0.1 and shades of gray for specific values: MW (35.9 to 36.3) is represented in light gray and ENACW ( 35.5 to 35.7 ) is represented in dark gray. Bathymetry is colored in black. 

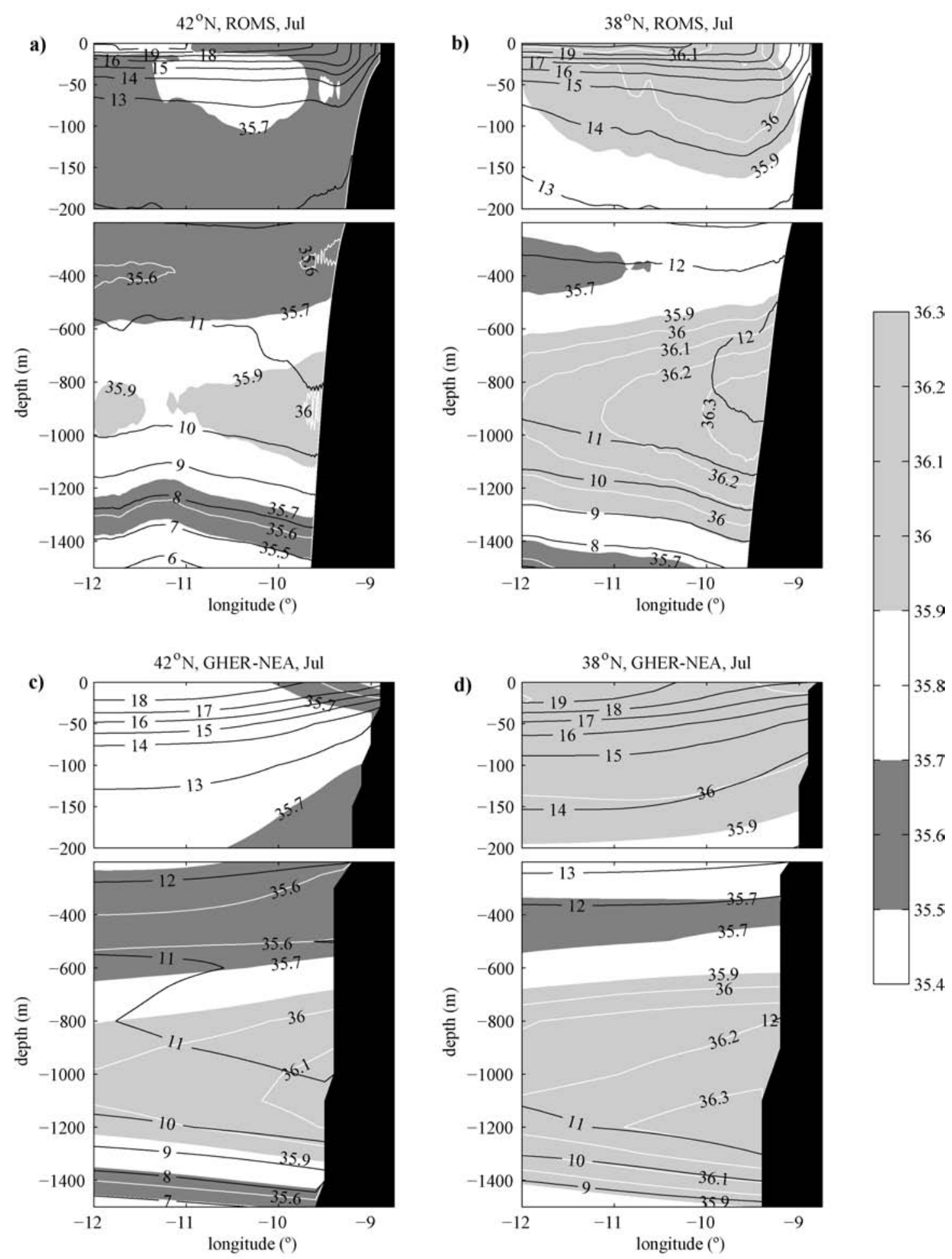

Figure 7 - Same as Figure 6 but for July, except temperature in the upper layers is represented in black contours every $1^{\circ} \mathrm{C}$. 


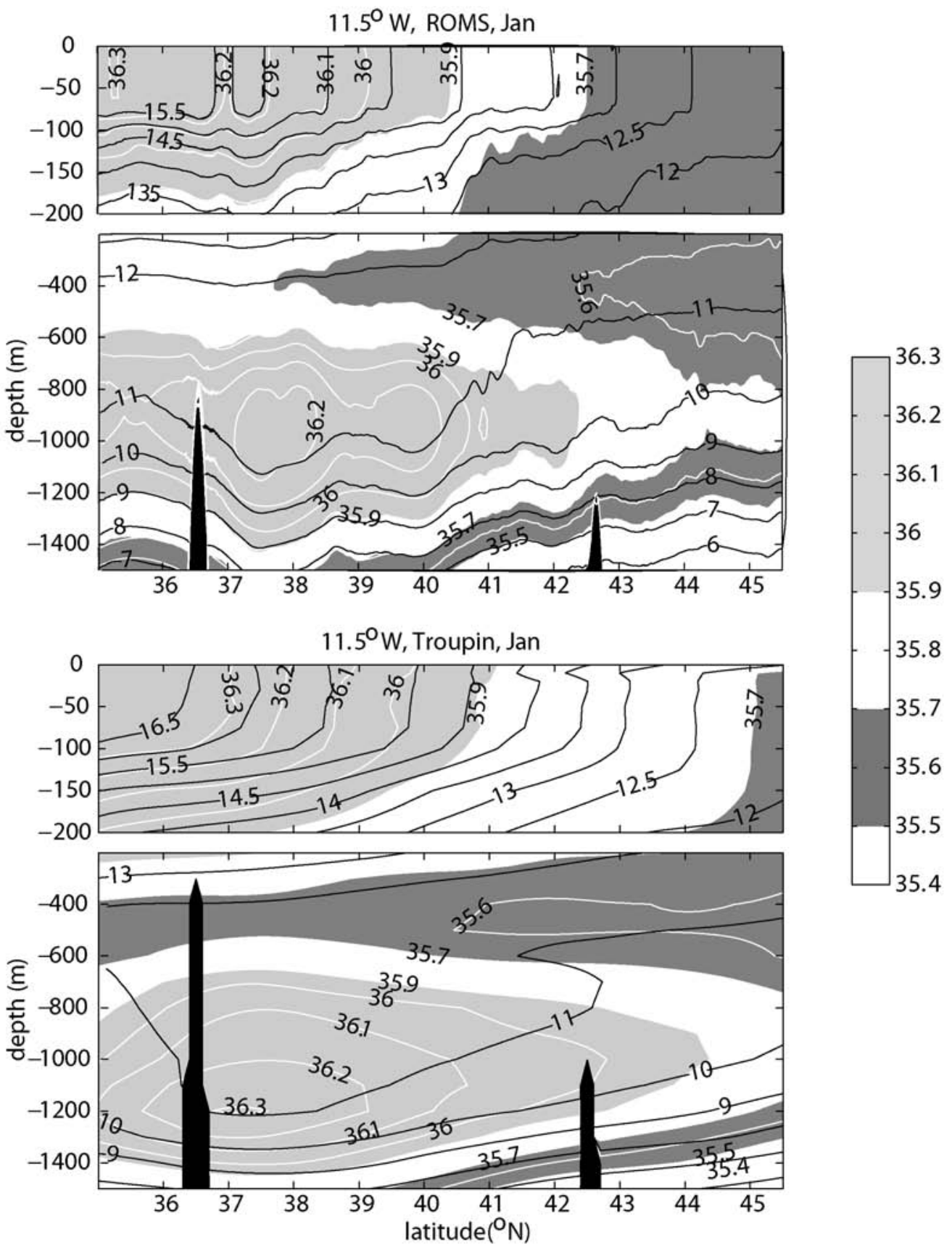

Figure 8 - Meridional section of temperature and salinity at $11.5^{\circ} \mathrm{W}$, for January: (a) 5-year means of ROMS output, (b) GHER-NEA climatology. 
a)

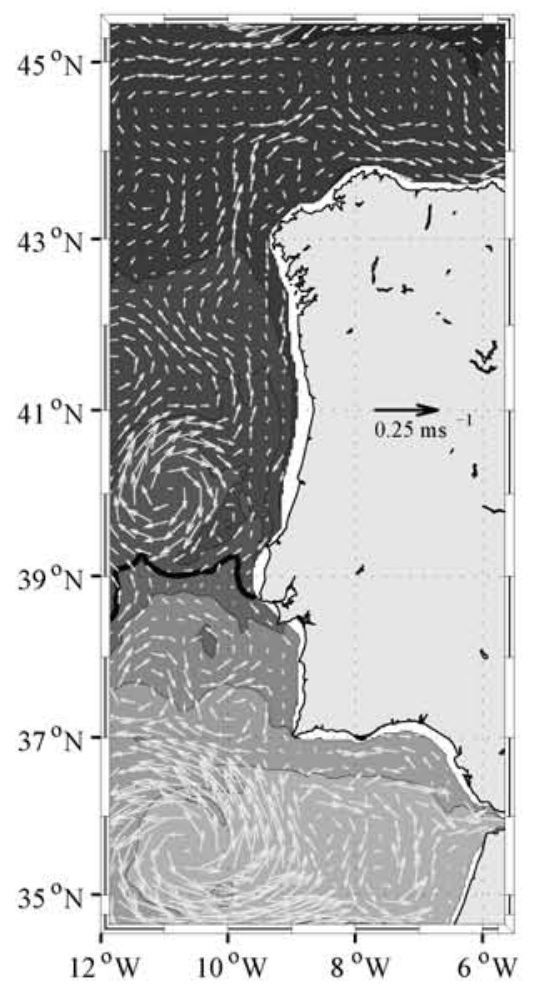

c)

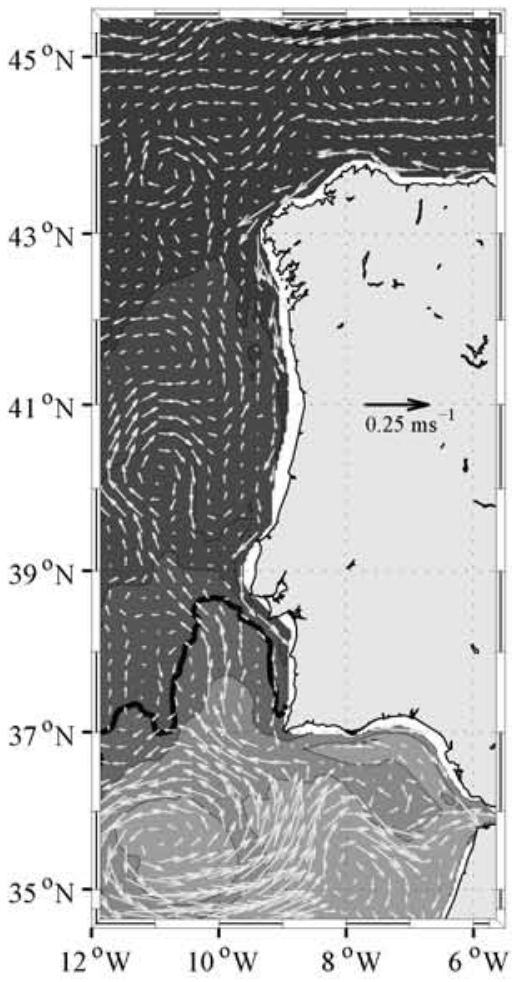

b) $\quad-1000 \mathrm{~m} \mathrm{Jan}$

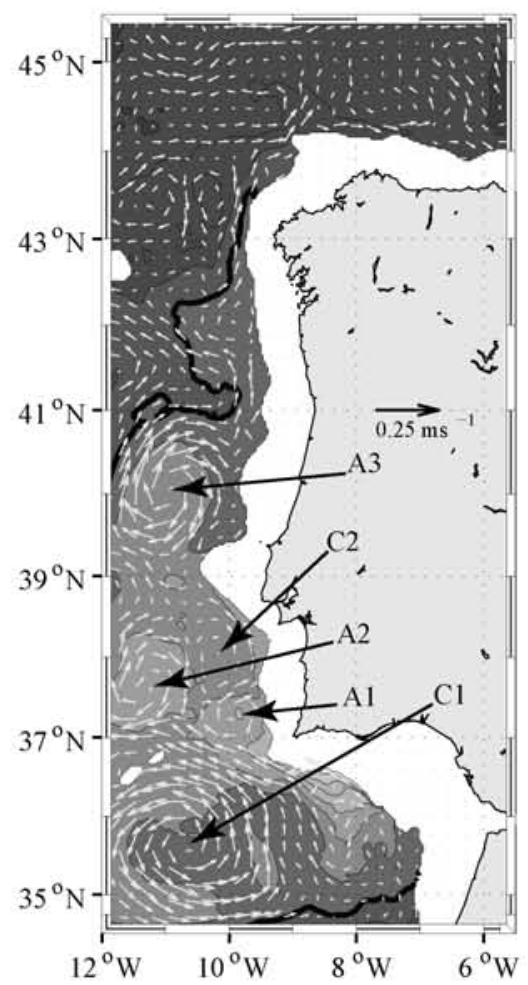

d) $\quad-1000 \mathrm{~m} \mathrm{Jul}$

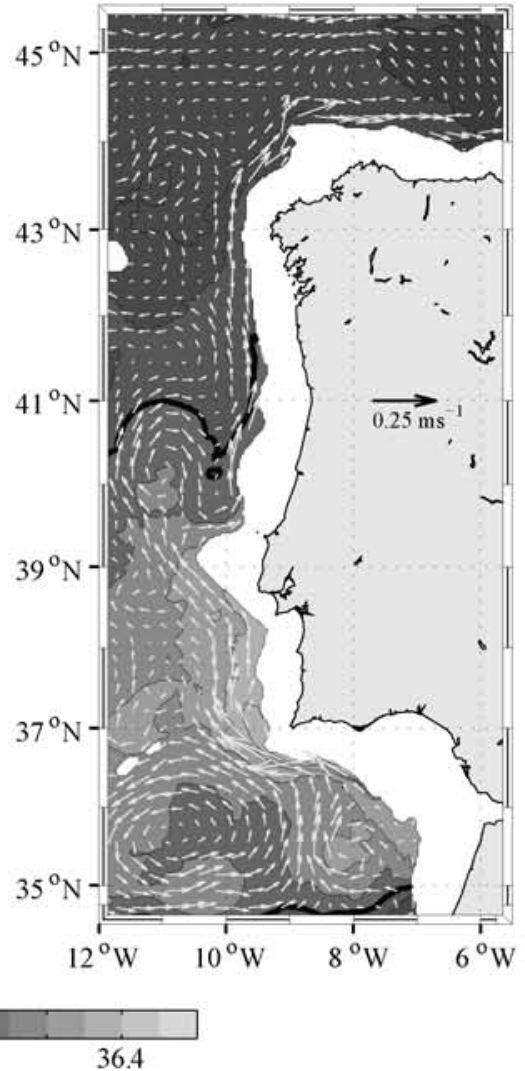

Figure 9 - Salinity and velocity fields for January (a, b) and July (c, d) at $50 \mathrm{~m}$ $(\mathrm{a}, \mathrm{c})$ and at $1000 \mathrm{~m} \mathrm{(b,d)}$. Isohalines are depicted every 0.2 (36 in thick black contours) and the vector scale is indicated on the map. For information regarding the pointing arrows, please refer to the text. 

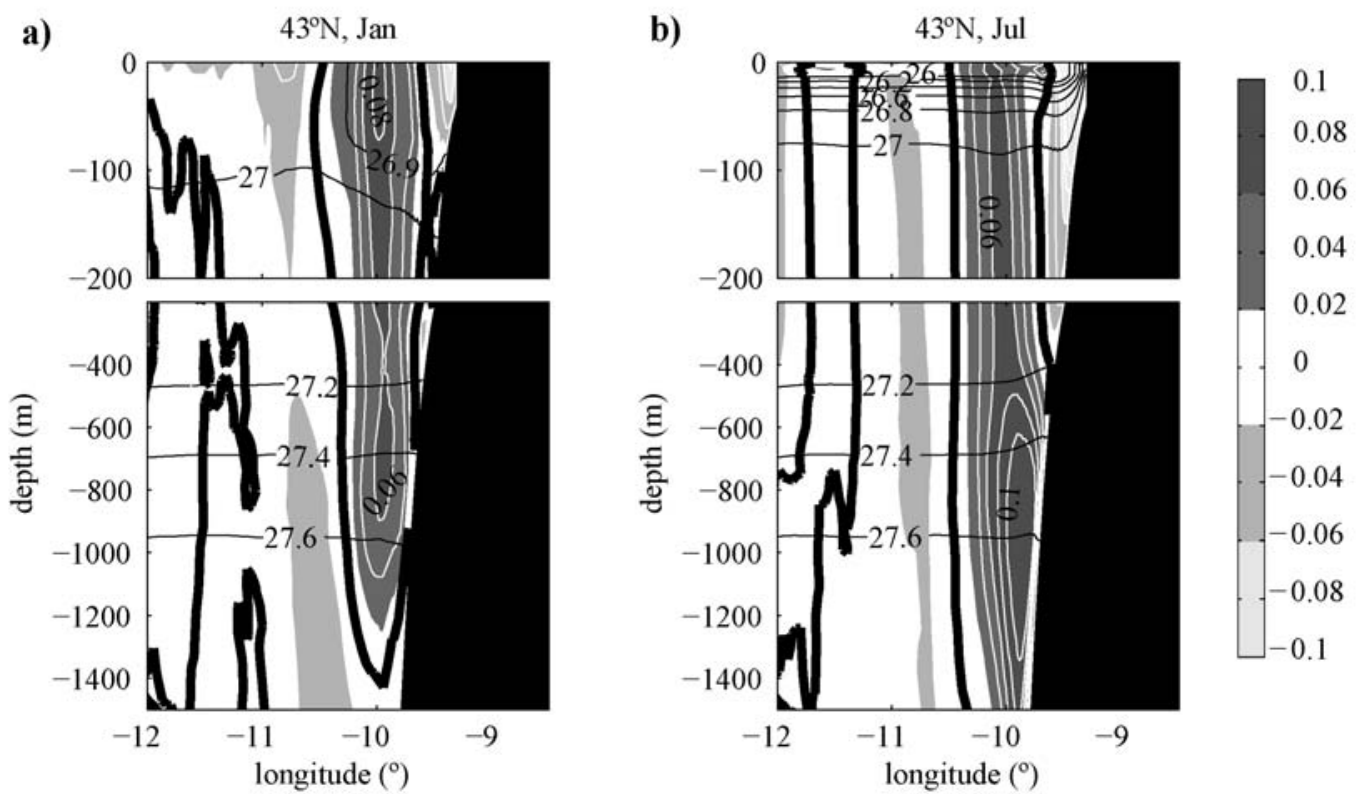

Figure 10 -Zonal sections, at $43^{\circ} \mathrm{N}$, of 5 -year means of potential density anomalies and meridional velocity for January (a) and July (b) down to $1500 \mathrm{~m}$ deep.

$\sigma_{\theta}$ is depicted every $0.2 \mathrm{~kg} \mathrm{~m}^{-3}$. The light shades of gray mark negative values below $-0.02 \mathrm{~m} . \mathrm{s}^{-1}$ and the dark shades of gray positive values above $0.02 \mathrm{~m} . \mathrm{s}^{-1}$. The thick contour is zero and the first $200 \mathrm{~m}$ are enlarged. 
$\omega$
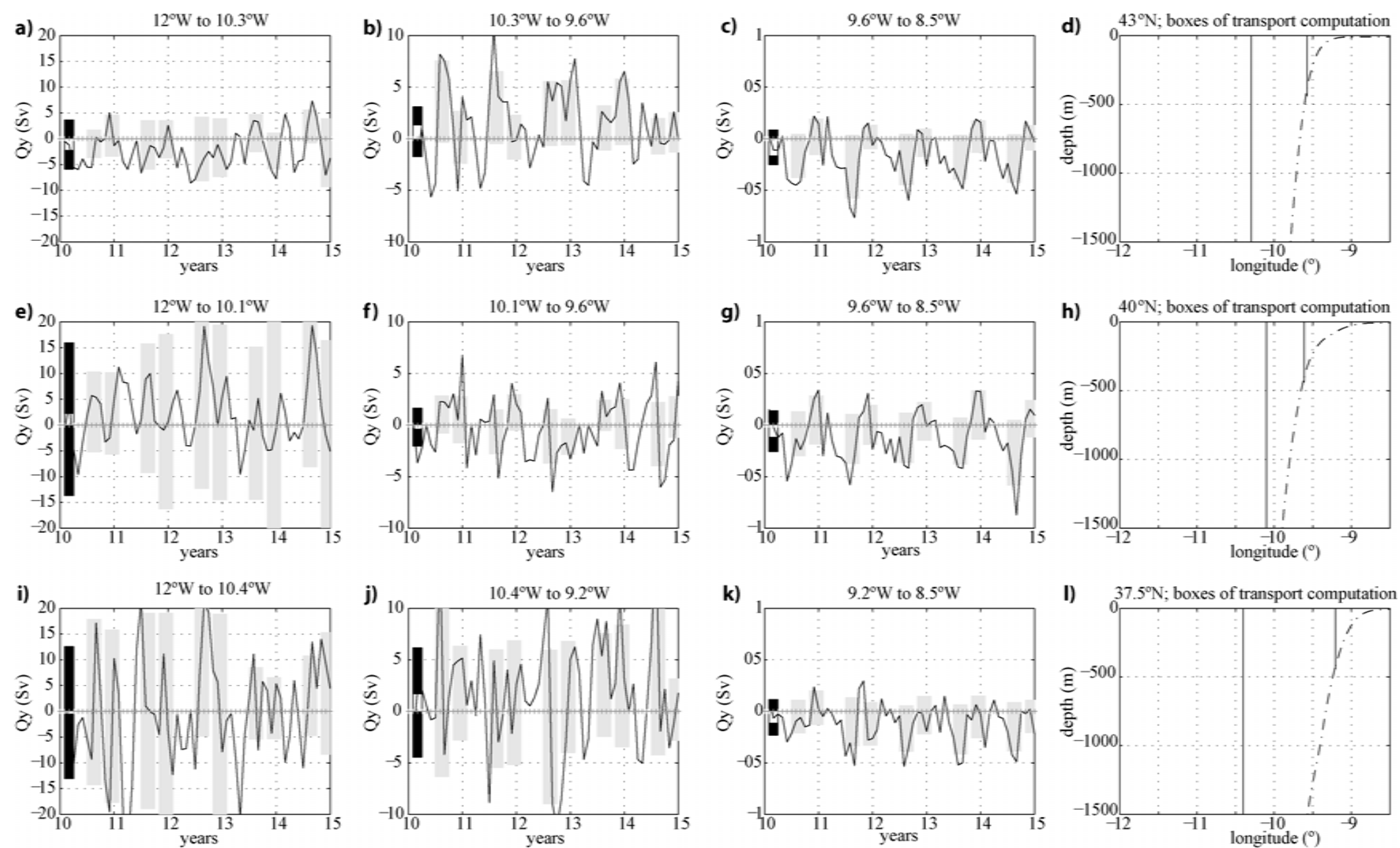

Figure 11 - Time series of meridional transport monthly means along: (a-d) $43^{\circ} \mathrm{N}$; (e-h) $40^{\circ} \mathrm{N}$; and (i-l) $37.5^{\circ} \mathrm{N}$. Each column corresponds to a sub-section represented in the rightmost column (d, h, l). From left to right: (a, e, i) offshore; (b, f, j) lower slope and adjacent upper layers; (c, g, k) shelf/upper slope (down to $400 \mathrm{~m}$ ). Seasonal averages (July, August, September - JAS - and November, December, January - NDJ) are plotted in shades of gray for northward and southward transports. To the left of each plot, total northward and southward averages are in black bars and the net average is in white bars. 

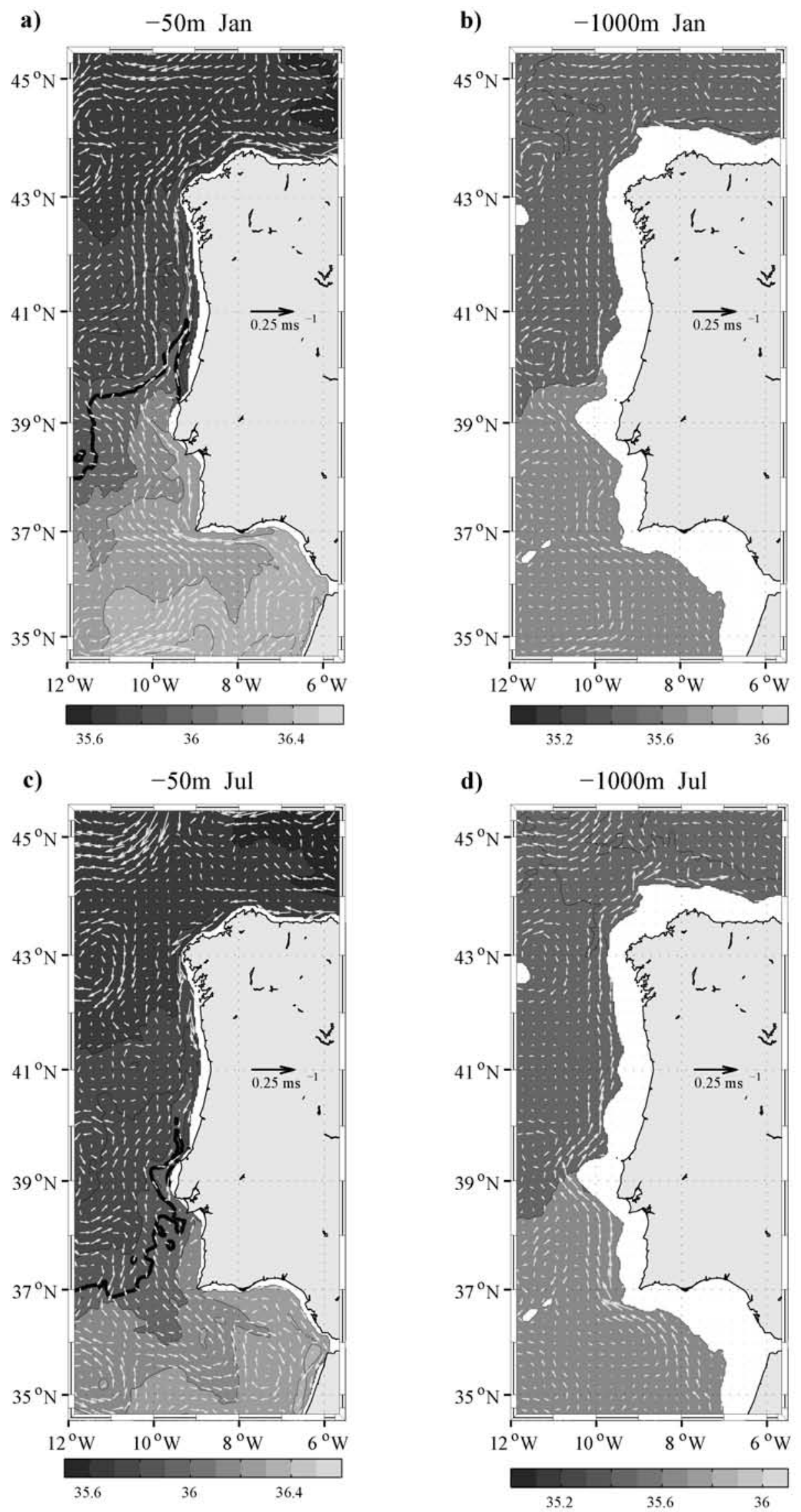

Figure 12 - Salinity and velocity fields for January (a, b) and July (c, d) at $50 \mathrm{~m}$ $(\mathrm{a}, \mathrm{c})$ and at $1000 \mathrm{~m} \mathrm{(b,d)}$ for the NMW run. Isohalines are depicted every 0.2 (36 in thick black contours) and the vector scale is indicated on the map. 
a)
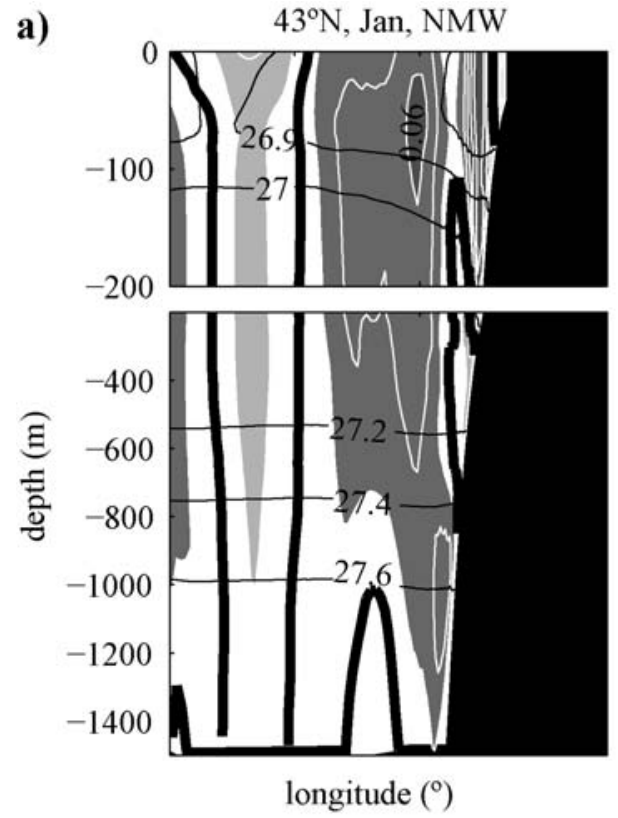

b)

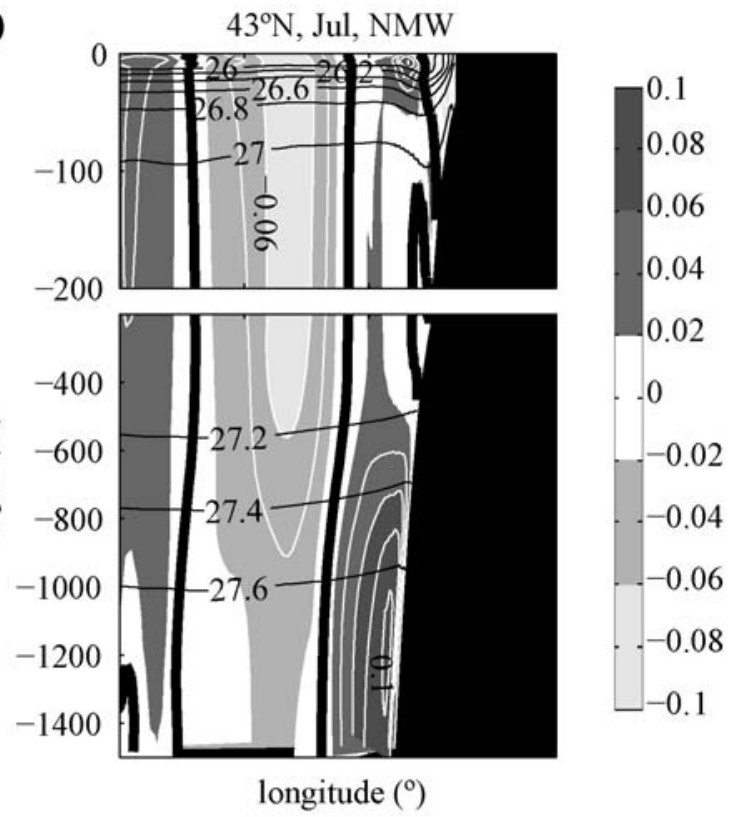

Figure 13 - Zonal sections, at $43^{\circ} \mathrm{N}$, of 5 -year means of potential density anomalies and meridional velocity for the NMW run for January (a) and July (b) down to $1500 \mathrm{~m}$ deep. $\sigma_{\theta}$ is depicted every $0.2 \mathrm{~kg} \mathrm{~m}^{-3}$. The light shades of gray mark negative values below $-0.02 \mathrm{~m} . \mathrm{s}^{-1}$ and the dark shades of gray positive values above $0.02 \mathrm{~m} \cdot \mathrm{s}^{-1}$. The thick contour is zero and the first $200 \mathrm{~m}$ are enlarged. 


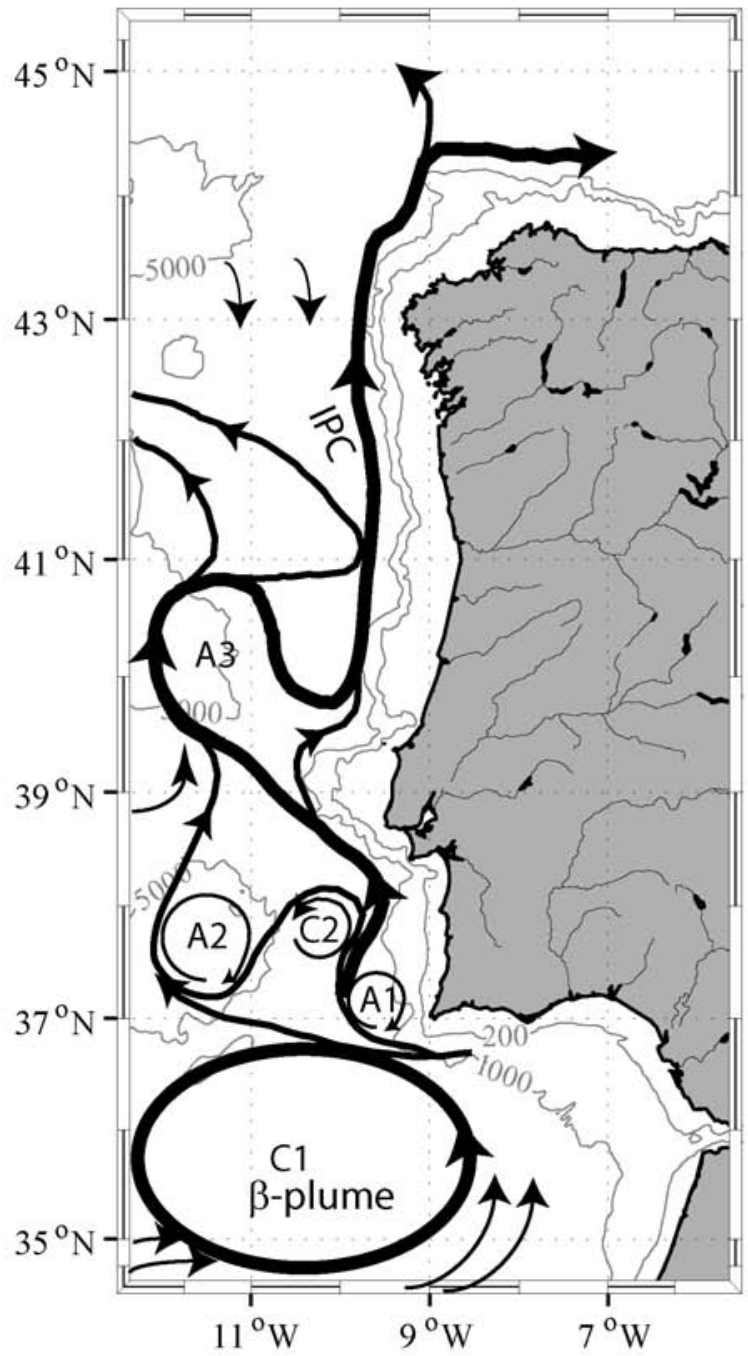

Figure $14-$ Schematic representation of the mean circulation at $1000 \mathrm{~m}$ as obtained from the present numerical modelling study, showing the principal paths of the obtained circulation structures, and the recirculation vorticity structures. 